\title{
49. MAGNETIC STRATIGRAPHY AND CHARACTERIZATION OF SEDIMENTS FROM THE NORTHEAST MARGIN OF AUSTRALIA AND THEIR RELATIONSHIP TO ENVIRONMENTAL CHANGE DURING THE QUATERNARY ${ }^{1}$
}

\author{
C.E. Barton, ${ }^{2}$ S.K. Omarzai, ${ }^{3}$ I. Alexander,${ }^{4}$ F. Peerdeman, ${ }^{5}$ and D. McNeill ${ }^{6}$
}

\begin{abstract}
This study is a synthesis of paleomagnetic and mineral magnetic results for Sites 819 through 823 of Ocean Drilling Program (ODP) Leg 133, which lie on a transect from the outer edge of the Great Barrier Reef (GBR) down the continental slope to the bottom of the Queensland Trough. Because of viscous remagnetization and pervasive overprinting, few reversal boundaries can be identified in these extremely high-resolution Quaternary sequences. Some of the magnetic instability, and the differences in the quality of the paleomagnetic signal among sites, can be explained in terms of the dissolution of primary iron oxides in the high near-surface geochemical gradients.

Well-defined changes in magnetic properties, notably susceptibility, reflect responses to glacio-eustatic sea-level fluctuations and changes in slope sedimentation processes resulting from formation of the GBR. Susceptibility can be used to correlate between adjacent holes at a given site to an accuracy of about $20 \mathrm{~cm}$. Among-site correlation of susceptibility is also possible for certain parts of the sequences and permits (tentative) extension of the reversal chronology. The reversal boundaries that can be identified are generally compatible with the calcareous nannofossil biostratigraphy and demonstrate a high level of biostratigraphic consistency among sites. A revised chronology based on an optimum match with the susceptibility stratigraphy is presented.

Throughout most of the sequences there is a strong inverse correlation both between magnetic susceptibility and calcium carbonate content, and between susceptibility and $\delta^{18} \mathrm{O}$. In the upper, post-GBR, sections a more complicated type of magnetic response occurs during glacial maxima and subsequent transgressions, resulting in a positive correlation between susceptibility and $\delta^{18} \mathrm{O}$.

Prior to and during formation of the outer-reef barrier, the sediments have relatively uniform magnetic properties showing multidomain behavior and displaying cyclic variations in susceptibility related to sea-level change. The susceptibility oscillations are controlled more by carbonate dilution than by variation in terrigenous influx. Establishment of the outer reef between 1.01 and $0.76 \mathrm{Ma}$ restricted the supply of sediment to the slope, causing a four-fold reduction in sedimentation rates and a transition from prograding to aggrading seismic geometries (see other chapters in this volume). The Brunhes/Matuyama boundary and the end of the transition period mark a change to lower and more subdued susceptibility oscillations with higher carbonate contents. The major change in magnetic properties comes at about $0.4 \mathrm{Ma}$ in the aggrading sequence, which contains prominent sharp susceptibility peaks associated with glacial cycles, with distinctive single-domain magnetite and mixed single-domain/superparamagnetic characteristics. Bacterial magnetite has been found in the sediments, particularly where there are high susceptibility peaks, but its importance has not yet been assessed. A possible explanation for the characteristic pattern of magnetic properties in the post-GBR glacial cycles can be found in terms of fluvio-deltaic processes and inter-reefal lagoonal reservoirs that develop when the shelf becomes exposed at low sea-level.
\end{abstract}

\section{INTRODUCTION}

During ODP Leg 133, a transect of sites was drilled, starting about $2 \mathrm{~km}$ beyond the outer edge of the Great Barrier Reef (GBR) (Site 821 ), down the upper continental slope (Sites 820,819 ), to the lower part of the slope (Site 822), and ending at the bottom of the Queensland Trough (Site 823). Site locations are shown in Figure 1. The upper Pliocene to recent sequences cored at these sites contain mixed carbonate-siliciclastic sediments that are characterized by alternations between terrigenous and carbonate-rich lithologies, thought to result from glacio-eustatic sea-level variations. Sedimentation rates are typically in the range of $10-50 \mathrm{~cm} / \mathrm{k} . \mathrm{y}$., thus giving a resolution comparable to that of lacustrine records. Sites on the upper part of the slope $(821,820$, and 819$)$ lie in shallow water depths, from 212 to

\footnotetext{
${ }_{1}^{1}$ McKenzie, J.A., Davies, P.J., Palmer-Julson, A., et al., 1993. Proc. ODP, Sci. Results, 133: College Station, TX (Ocean Drilling Program).

${ }^{2}$ Australian Geological Survey Organisation, P.O. Box 378, Canberra ACT 2601, Australia.

${ }^{3}$ Earth Sciences Board, University of California, Santa Cruz, CA 95064, U.S.A.

${ }^{4}$ Dept. of Geology and Geophysics, University of Edinburgh, Edinburgh EH9 3JZ, Scotland.

${ }^{5}$ Research School of Earth Sciences, Australian National University, Canberra ACT 2601, Australia

${ }^{6}$ Division of Marine Geology and Geophysics, Rosenstiel School of Marine and Atmospheric Science, University of Miami, Miami, FL 33149, U.S.A.
}

$565 \mathrm{~m}$, and are therefore particularly sensitive to the effects of sealevel fluctuations.

Paleomagnetic work was undertaken to provide a reversal chronology and to investigate the relationship between changes in mineral magnetic properties and environmental factors, particularly glacioeustatic sea-level variations and reef development. Susceptibility logging has proved to be useful for monitoring environmental change, but is by no means unique in this regard and often provides information that can also be obtained from other environmentally sensitive parameters, notably calcium carbonate content, grain size and $\delta^{18} \mathrm{O}$. However, the use of susceptibility is convenient because the measurements are easy, rapid, and nondestructive. Susceptibility provides a blanket response combining the effects of changes in the quantity, mineralogy and grain size of the magnetic fraction and is therefore a useful "catch-all" magnetic parameter (Thompson and Oldfield, 1986). Further rock magnetic measurements will be needed to resolve the various contributions to the susceptibility. The results from Site 820 (Barton et al., this volume) demonstrate the importance of resolving these contributions. The calcareous nannofossil age datums of Wei and Gartner (this volume) provide the best available chronological framework for the sites in question. We use the abbreviation WG/0.075 to denote Wei and Gartner's datum at $0.075 \mathrm{Ma}$ (the first occurrence of Emiliania huxleyi Acme) and likewise for the other datums (listed in Table 9). Magnetostratigraphic ages are reported according to the time scale of Berggren et al. (1985a, 1985b), which is the convention used for Leg 133. Revised time scales that incorporate astronomical calibrations are 


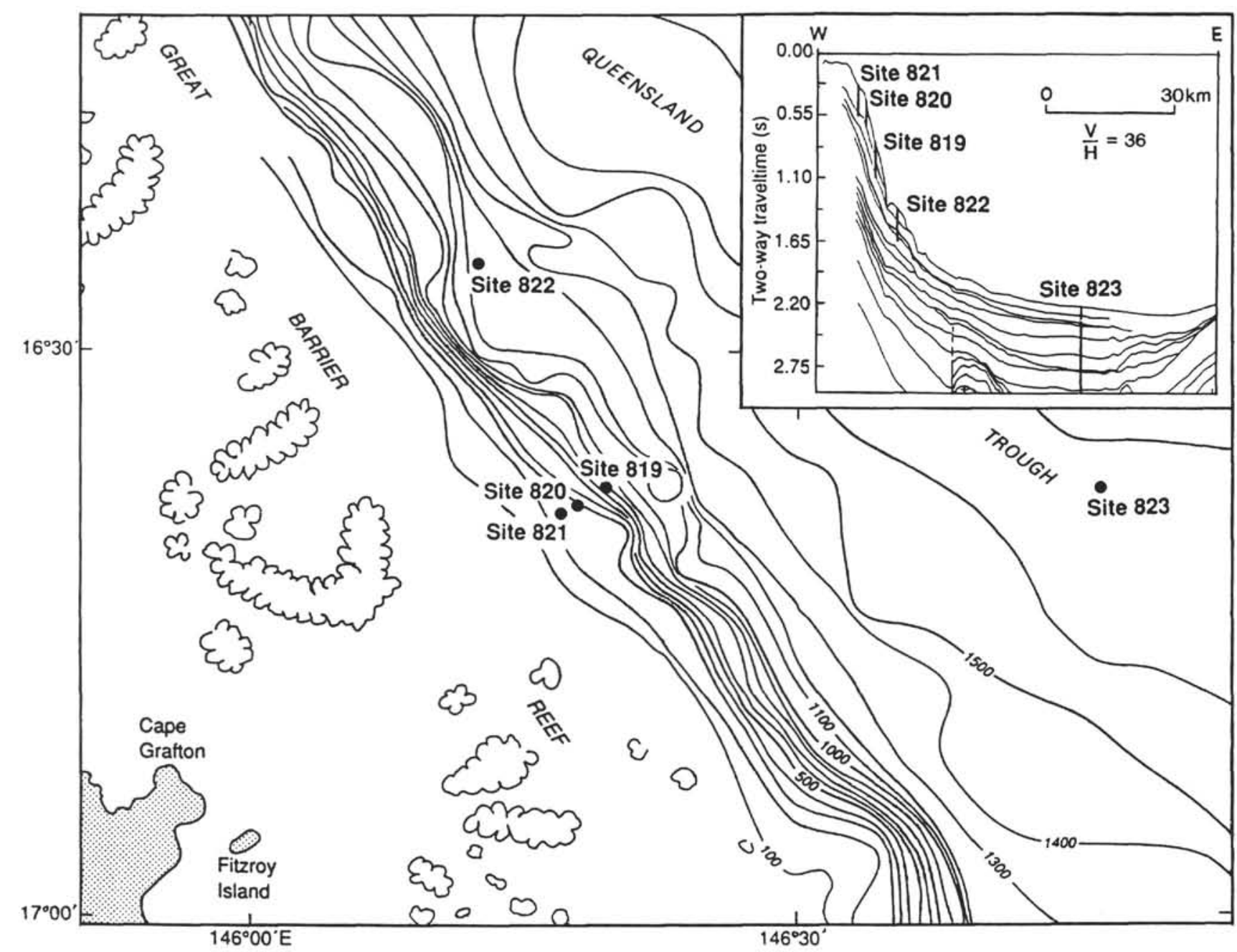

Figure 1. Locations and bathymetry for Leg 133, Sites 819 through 823 , northeastern margin of Australia. A cross-section of the transect of sites from the shelf edge to the Queensland Trough is shown in the inset.

now available (e.g., Cande and Kent, 1992). Unless stated otherwise, sequences of event are assumed to be in chronological order (e.g., "a rise in susceptibility at $7.5 \mathrm{mbsf}$ " means that susceptibility is low below and high above 7.5 meters below seafloor (mbsf).

In the ensuing discussion, the terms "magnetite" and "hematite" are generally used in a generic sense to denote mineral assemblages that have magnetite- or hematite-type responses to rock property tests performed at room temperature. Detailed microscopy, magnetic mineral analysis, and high-temperature thermo-magnetic work have not yet been undertaken, so a more refined treatment of the magnetic mineralogy is not possible at this stage. The magnetic results summarized in this paper come from the following sources:

1. Davies, McKenzie, Palmer-Julson, et al. (1991): shipboard wholecore natural remanent magnetization (NRM), alternating field (AF) cleaned magnetization, and volume susceptibility data for all sites;

2. S.K. Omarzai (pers. comm., 1992): step-demagnetization results for Sites 821 (477 samples), 819 (214 samples), 822 (237 samples), and 823 (279 samples);

3. Peerdeman and Davies (this volume): susceptibility data for the upper $12 \mathrm{~m}$ of Hole $820 \mathrm{~A}$;

4. Alexander et al. (this volume): remanence and rock magnetic results for Hole 819A;
5. Barton et al. (this volume): remanence and rock magnetic results for Site 820 (Holes $820 \mathrm{~A}$ and $820 \mathrm{~B}$ );

6. Barton (this volume): remanence and rock magnetic results for Site 823 (0-236 mbsf only);

7. D. McNeill (pers. comm., 1991): rock-magnetic measurements on miscellaneous samples.

To avoid repetitive referencing, no specific acknowledgement is made in the text when the source of data or conclusion is obvious from the context. Conversions from the cgs units used herein to SI units are as follows: magnetic field strength $(H): 1$ oersted $(\mathrm{Oe})=10^{3} / 4 \pi$ $\mathrm{A} / \mathrm{m}$; magnetic flux density $(B): 1$ gauss $(\mathrm{G})=10^{-4}$ tesla; thus, a magnetic field of strength 1 Oe produces a magnetic flux density of 0.1 millitesla $(\mathrm{mT})$ in a vacuum; intensity of magnetization $=1$ microgauss $(\mu \mathrm{G})=10^{-3} \mathrm{~A} / \mathrm{m}$; volume susceptibility $(K): 1 \mathrm{G} / \mathrm{Oe}=$ $1 / 4 \pi$ SI units (dimensionless).

\section{SITE AND CORE DESCRIPTIONS}

Information about site locations and core penetrations are summarized in Table 1. Most attention has been paid to Sites 821, 820, and 819 , located on the upper continental slope adjacent to Grafton Passage, with bottom ages of $<1.48 \mathrm{Ma}$. Site 822 is some $25 \mathrm{~km}$ 
Table 1. Leg 133 hole locations and statistics.

\begin{tabular}{|c|c|c|c|c|c|c|c|}
\hline \multirow[b]{2}{*}{ Site } & \multirow{2}{*}{$\begin{array}{l}\text { Latitude } \\
\text { (South) }\end{array}$} & \multirow{2}{*}{$\begin{array}{l}\text { Longitude } \\
\text { (East) }\end{array}$} & \multirow{2}{*}{$\begin{array}{l}\text { Water } \\
\text { depth } \\
\text { (m) }\end{array}$} & \multicolumn{2}{|c|}{ Penetration (m) } & \multirow{2}{*}{$\begin{array}{l}\text { Bottom } \\
\text { age } \\
\text { (Ma) }\end{array}$} & \multirow[b]{2}{*}{ Notes } \\
\hline & & & & total & APC & & \\
\hline 821 & $16^{\circ} 38.793^{\prime}$ & $146^{\circ} 17.366^{\prime}$ & 212 & 400.0 & 165.9 & $<1.48$ & $46 \mathrm{~km}$ from shore \\
\hline 820 & $16^{\circ} 38.220^{\prime}$ & $146^{\circ} 18.224^{\prime}$ & 278 & 400.0 & 160.2 & $<1.48$ & $1.9 \mathrm{~km} \mathrm{NE}$ of Site 821 \\
\hline 819 & $16^{\circ} 37.439^{\prime}$ & $146^{\circ} 19.486^{\prime}$ & 565 & 400.0 & 123.0 & $<1.48$ & $2.7 \mathrm{~km}$ NE of Site 820 \\
\hline 822 & $16^{\circ} 25.379^{\prime}$ & $146^{\circ} 12.904^{\prime}$ & 955 & 433.9 & 95.9 & $>2.60$ & $25 \mathrm{~km} \mathrm{NW}$ of Site 819 \\
\hline 823 & $16^{\circ} 36.981^{\prime}$ & $146^{\circ} 36.045^{\prime}$ & 1638 & 1011.0 & 120.5 & 10.8 & $29 \mathrm{~km} \mathrm{E}$ of Site 819 \\
\hline
\end{tabular}

Note: $\mathrm{APC}=$ advanced hydraulic piston corer.

northwest of these three main sites and is located in the middle of the lower slope, with a bottom age of $<2.6 \mathrm{Ma}$. Site 823 , located at the bottom of the Queensland Trough, contains a longer record (to 10.8 Ma). Grafton Passage is a navigable channel through the outer Great Barrier Reef (GBR), but does not today correspond to any significant valley on the slope (see Figure 1 of Feary and Jarrard, this volume). However, during the progradational regime prior to $1 \mathrm{Ma}$ (described by Davies, McKenzie, Palmer-Julson, et al., 1991, and discussed later in this study), Sites 819 through 821 lay on the northeastern flank of a submarine valley that must have been a channel for downslope sediment transport (Feary and Jarrard; Feary et al., this volume). Sites 819 through 822 contain a relatively uniform succession of greenish gray, clayey, calcareous mudstones and bioclastic wackestones/packstones. These sites are characterized by alternating cycles of terrigenous- and carbonate-rich sediments. Site 823 contains numerous gravity-flow deposits. Bioturbation mottling has been noted (for example in much of Site 820, in some cases completely disrupting thinner beds; Feary and Jarrard, this volume). However, the scale of bioturbation is considered to be too small to blur significantly the magnetic records considered here. The main characteristics of the sequences cored at each site are described in Davies, McKenzie, Palmer-Julson, et al. (1991) and can be summarized as follows:

1. Site 821 is closest to the outer edge of the GBR, about $6 \mathrm{~km}$ east of Euston Reef. Shelf-edge reefs occur only $2 \mathrm{~km}$ west of Site 821 . The seismic sections indicate that the sequences at Sites 821 and 820 are similar and have similar sedimentation rates.

2. Site 820 contains greenish-gray to dark greenish-gray mud-sized wackestones, interbedded with coarser greenish gray bioclastic packstones. Well-defined upward-coarsening cyclic variations in properties occur below 146 mbsf (Units II and III); episodic alternations between coarse and fine intervals occur above $146 \mathrm{mbsf}$ (Unit I). There is a prominent erosional unconformity at the boundary. A planktonic ( $\mathrm{Glo}$ bigerinoides ruber) oxygen isotope record is available for Hole $820 \mathrm{~A}$ down to $134.3 \mathrm{mbsf}$ (Peerdeman et al., this volume).

3. Site 819 lies less than $200 \mathrm{~m}$ west of a major erosional/slump scarp. The sequence is characterized by rhythmically bedded hemipelagic carbonate and siliciclastic sand and mud, with well-defined series of upward-coarsening couplets. A possible slump surface was identified at $32.5 \mathrm{mbsf}$ and the biostratigraphic interval from 0.275 to $0.465 \mathrm{Ma}$ is either missing or highly condensed between 29.4 and 32.4 mbsf. Two oxygen isotope records are available for Site 819: benthic (Cibicidoides spp.) down to $62 \mathrm{mbsf}$, and planktonic (Globigerinoides ruber) down to $120 \mathrm{mbsf}$ (Alexander et al., this volume).

4. Site 822 is located on top of a mounded and channelled complex on the lower slope, about $14 \mathrm{~km}$ east of the nearest reef (Onyx Reef). The section recovered is composed mainly of muds with varying amounts of carbonate ooze and terrigenous clays and lesser amounts of bioclastic and terrigenous (mostly quartz) sand and silt. The sequence is distinctly cyclical, as seen in both color and compositional variations that are related to the proportions of carbonate and terrigenous sediments. A possible hiatus from 0.275 to $0.465 \mathrm{Ma}$ occurs at 21.8 mbsf (nannofossil Subzone CN14b is missing). The rest of the section has no obvious lithostratigraphic or biostratigraphic breaks, although the seismic data suggest that other unconformities may exist.

5. Site 823 contains numerous gravity-flow deposits (more than 2000; Watts et al., this volume). Despite this the paleontological results indicate a monotonic time sequence downcore and the material in the gravity flows is considered to be contemporaneous with the material being deposited in the normal manner (Davies, McKenzie, Palmer-Julson, et al., 1991).

An important transition from prograding to aggrading seismic geometries is marked by a change from "siliciclastic-type" to "carbonate-type" depositional regimes and a large (typically four-fold) reduction in sedimentation rates (Davies, McKenzie, Palmer-Julson, et al., 1991; Feary and Jarrard, this volume; Glenn et al., this volume). The transition zone, dated at 1.01 to $0.76 \mathrm{Ma}$ by Feary and Jarrard (this volume), occurs at Site 821 at about 172-224 mbsf and at Site 820 at $146-208$ mbsf. At Sites 819 and 822 the transition zone is probably not represented because of the hiatuses at 32 mbsf and 22 mbsf, respectively. The sequence boundary between the prograding and aggrading geometries is marked by an erosional unconformity in the upper slope sites. The prograding sequence is characterized by rhythmic couplets, mostly upward-coarsening, that are thought to reflect regular cyclic variations in sea-level. In the aggrading sequence the regular cyclicity is replaced by more episodic, intensified variations in sediment properties with highly variable sedimentation rates.

\section{NATURAL MAGNETIZATION AND SUSCEPTIBILITY}

Shipboard measurements were made at $10-\mathrm{cm}$ intervals on the archive halves of whole cores, comprising NRM, magnetic remanence after AF cleaning at 150 Oe peak field, and initial low-field magnetic susceptibility per unit volume $(K)$. The results are reported in Davies, McKenzie, Palmer-Julson, et al. (1991). Subsamples for shore-based paleomagnetic work were collected generally at intervals of 20 or $40 \mathrm{~cm}$. S.K. Omarzai (pers. comm., 1992) has undertaken extensive step-wise demagnetization work on all sites except Site 820 and found little difference in the effectiveness of thermal and AF methods for isolating stable components of remanence. Thus, he used the $\mathrm{AF}$ method for more than $90 \%$ of the specimens demagnetized using steps of 25 or 50 Oe up to peak fields of 500 to 600 Oe. Barton et al. (this volume) used AF demagnetization only for Site 820 .

The core orientation system is not reliable, and achieved only a $54 \%$ success rate at Sites 819 through 823 . Furthermore, the results from Site 820 show that declinations for adjacent oriented cores do not match, and that orientations may be in error by up to $60^{\circ}$ or more (Barton et al., this volume). There is also a trend in declination data from each core, which suggests that most cores are twisted relative to the core liner, typically by $10^{\circ}-20^{\circ}$. As is commonly the case in nonequatorial situations, the inclination data are the most convenient and useful for identifying reversals and declination data make little, or no, contribution.

Generally, excellent agreement is seen between the subsample data and shipboard whole-core measurements of both NRM and susceptibility. However, laboratory-determined subsample NRM intensities and volume susceptibilities average about $20 \%$ lower and $50 \%$ lower, respectively, than the whole-core shipboard values. Part of this may be a calibration problem, but it is common to find that the NRM intensity of fresh sediments decays with time. The fact that there are several zones where the subsample and whole-core intensities agree closely suggests that the latter may be the case.

NRM intensities are similar at each site, ranging from about 0.1 to $10 \mu \mathrm{G}$, except for Site 823 where NRMs are approximately double those at the other sites. Susceptibilities range typically from about 1 to $20 \mu \mathrm{G} / \mathrm{Oe}$ at each site, including Site 823 , with some prominent sharp peaks in the upper part of the aggrading sequences. Average 
Table 2. NRM intensity and volume susceptibility statistics.

\begin{tabular}{|c|c|c|c|c|c|c|c|}
\hline \multirow[b]{2}{*}{ Site } & \multirow{2}{*}{$\begin{array}{l}\text { Depth } \\
\text { range } \\
\text { (mbsf) }\end{array}$} & \multicolumn{3}{|c|}{ NRM intensity $(\mu G)$} & \multicolumn{3}{|c|}{ Susceptibility $(\mu \mathrm{G} / \mathrm{Oe})$} \\
\hline & & Mean & Sd & $\begin{array}{c}\text { Interquartile } \\
\text { mean }\end{array}$ & Mean & Sd & $\begin{array}{l}\text { Interquartile } \\
\text { mean }\end{array}$ \\
\hline 821 & $0-400.0$ & 1.90 & 4.08 & 0.77 & 6.82 & 6.29 & 5.44 \\
\hline 820 & $0-400.0$ & 1.97 & 5.32 & 0.72 & 6.56 & 5.35 & 5.37 \\
\hline 819 & $0-400.0$ & 1.55 & 3.84 & 0.74 & 8.85 & 5.40 & 8.43 \\
\hline 822 & $0-434.0$ & 1.73 & 4.10 & 0.85 & 9.29 & 5.34 & 9.04 \\
\hline 823 & $0-352.7$ & 3.20 & 7.35 & 1.27 & 8.71 & 6.15 & 7.49 \\
\hline
\end{tabular}

Note: Statistics are for whole-core data only, $\mathrm{Sd}=$ standard deviation.

values of whole-core NRM intensity and susceptibility are summarized in Table 2. Downhole variations in susceptibility are generally a reflection of differing terrigenous contents. For example, susceptibilities in Unit II at Site 822 are typically higher $(\sim 10 \mu \mathrm{G} / \mathrm{Oe})$ than in Unit I (typically $\sim 3 \mu \mathrm{G} / \mathrm{Oe}$ ) because of the higher terrigenous content (darker color) in Unit II.

One may infer from Table 2 that the magnetic mineral content is similar at all the sites, and that no trend toward decreasing magnetic mineral concentration at greater distances from the coast occurred. This suggests that hemipelagic sediments of constant magnetic (i.e., terrigenous) concentration are transported offshore to form the bulk of the sediment column (rather than in-situ production of carbonate and an offshore-decreasing admixture of terrigenous material). The enhanced NRM intensities at Site 823, with no accompanying enhancement of susceptibility, suggests that fine-grained (singledomain, SD) terrigenous material is transported in suspension down the slope and accumulates preferentially at the base of the trough.

At all sites, well-defined rhythmic oscillations in magnetic susceptibility (and NRM intensity) relate closely to cyclic variations in lithology, in particular to variations in the relative concentration of terrigenous material and carbonates (Davies, McKenzie, Palmer-Julson, et al., 1991). Except at Site 822, the upper parts of the magnetic records (above WG/0.465) feature several prominent peaks (Fig. 2). Note also that there is an interval of low susceptibility below WG/0.465 (evident at all sites). Magnetic susceptibility is strongly correlated to carbonate content, grain size and $\delta^{18} \mathrm{O}$ (as noted in several other papers in this volume, and discussed in more detail later in this paper). Both the rhythmic variations in susceptibility and the peaks are thought to be sea-level controlled, albeit by different mechanisms. Magnetic susceptibility can be used to correlate accurately between holes (within $20 \mathrm{~cm}$ for Holes $820 \mathrm{~A}$ and $820 \mathrm{~B}$ ) and also, with less accuracy, among sites for many parts of the sequences.

Sites 821,820 , and 823 , where the most severe magnetic overprinting occurs, have low values of median destructive field (MDF), ranging typically from 30 to $150 \mathrm{Oe}$, with a downcore gradual decreasing trend that probably reflects progressive diagenetic alteration. At the intervening Sites 819 and 822 , MDF's show more variability, with moderately high values $(200-300 \mathrm{Oe})$ in the lower halves of the sequences.

At Site 820, values of MDF are consistently lower than at Site 821 (except in the uppermost $10 \mathrm{mbsf}$, where the reverse is true). Normally, this would be taken to indicate that stable SD remanence is more dominant at Site 821. However, the high scatter in directions and the evidence for overprinting at Site 821 indicate that the high coercivity component at Site 821 is largely of viscous remanent magnetization (VRM) or chemical remanent magnetization (CRM) origin.

MDF values are high in the near-surface sediments at each of the upper-slope sites $(821,820$, and 819) and show a steep downcore decline at about $10 \mathrm{mbsf}$. More gradual downward-decreasing trends of MDF occur at Sites 822 (0-19 mbsf) and 823 (0-75 mbsf). We attribute the high surface values of MDF to the presence of primary detrital iron oxides (mainly SD magnetite) that are progressively removed by sulfate reduction processes. Values of the modified Koenigsberger ratios $(Q=\mathrm{NRM}$ intensity $/ K)$ are generally low at all sites, seldom exceeding $1.0 \mathrm{Oe}$. This is consistent with the generally poor magnetic stability of the sediments. Variations of $Q$-ratio at Sites 821 and 820 are similar, ranging typically between 0.1 and $0.5 \mathrm{Oe}$, with swings as low as 0.03 and as high as $2 \mathrm{Oe}$. The highest values tend to coincide with peaks of susceptibility (and NRM).

\section{MAGNETIC POLARITY STRATIGRAPHY}

The magnetostratigraphic records obtained have been singularly bad as a result of pervasive VRM effects and overprinting, and few reversal boundaries are well-defined. However, with some creative intersite stratigraphy, it has been possible to extract chronological information from each of the sites except Site 823. Some of the shipboard interpretations (Davies, McKenzie, Palmer-Julson, et al., 1991) require substantial revision in the light of the new subsample data and recognition of the widespread nature of overprinting.

In general, the quality of the paleomagnetic record degenerates with increasing depth. This is common in hemipelagic to pelagic marine carbonate sediments (Barton and Bloemendal, 1985) and probably results from a combination of the removal of primary iron oxides by sulfate reduction processes, diagenetic alteration, and dispersal of directions during sediment compaction. Evidence exists that at least some, and possibly much, of the magnetite present is of bacterial origin (P. Hesse, pers. comm., 1991). If so, then only a moderate amount of dissolution would bring the grain size into the sub-SD range and produce unstable behavior. There is a noticeable increase of inclination scatter in the sections drilled using the rotary extended core barrel (XCB), for example, below 146 mbsf at Hole 821A.

Selected parts of the inclination records, after magnetic cleaning, are shown in Figure 3. The tramlines on the plots denote the axial dipole inclinations $\left( \pm 31^{\circ}\right)$. Subsequent laboratory measurements have not substantially altered the picture obtained from the shipboard records. The main results for each site are summarized later in this chapter. To make some sensible interpretation of the poor records available, we have used the criterion that only data with moderately high MDF values should be considered. This generally produces consistent results and brings the interpretations into broad agreement with the biostratigraphic ages.

\section{Polarity at Sites 821 and 820}

Inclination plots for parts of Holes $821 \mathrm{~A}$ and $820 \mathrm{~B}$ have already been shown in Figures $3 \mathrm{~A}$ and $3 \mathrm{~B}$; plots for all the subsample results for Hole 821A are shown in Figure 4. Subsample directions in Hole $821 \mathrm{~A}$ are selected stable, characteristic directions obtained from detailed progressive demagnetization (S.K. Omarzai, unpubl. data, 1992). Superimposed on the subsample results is a plot of the MDF. No reversal boundaries can be identified unambiguously in either Site 821 or Site 820 . However, at each site there is a transition downcore to an increase in inclination scatter, accompanied by the onset of intermediate and reversed directions. This is most evident in the shipboard AF-cleaned whole-core data (Figs. 3A and 3B). The transition occurs at approximately 137 to $155 \mathrm{mbsf}$ at Hole $821 \mathrm{~A}, 132$ to 143 mbsf at Hole 820B, and 126+ mbsf at Hole 820A (Hole 820A stops short of the end of the interval). Selecting the top of the transition is difficult and subjective; the lower boundary is more clearly defined. It is probable that the Brunhes/Matuyama $(\mathrm{B} / \mathrm{M})$ boundary lies within the transition. This would be consistent with the biostratigraphy, with the seismic evidence that sedimentation rates at Sites 821 and 820 are similar, and with the placement by Peerdeman et al. (this volume) of isotope stage 19.1 at $143 \mathrm{mbsf}$ in Hole $820 \mathrm{~B}$ (stage 19.1 is generally considered to be near the B/M boundary; deMenocal et al., 1990).

Note that the high-coercivity, characteristic inclinations in Hole 821 obtained by S.K. Omarzai (unpubl. data, 1992) from detailed progressive demagnetizations indicate consistently normal polarity 
throughout the sequence, with only a few isolated reversed directions (Fig. 4). As all other evidence indicates that the sequence is older than the Brunhes, we must conclude that the overprint signal has a high coercivity. Moon and Merrill (1986) showed that high coercivity VRM can occur, and there always remains the possibility that the high coercivity overprint is partly of post-depositional chemical origin. Below the estimated position of the B/M boundary, the records at both Sites 821 and 820 are too poor to merit any sort of polarity interpretation. There are several short intervals in the Brunhes-age part at Site 821 that might be evidence of geomagnetic excursions (e.g., 9.5-11, $35-38.8,55.5,73.5,114.5-121.5$, and $143-146$ mbsf). None of these intervals is unduly influenced by possible coring disturbance at the tops or bottoms of cores. However, comparison among Holes 821A, $820 \mathrm{~A}$ and $820 \mathrm{~B}$, using both whole-core and subsample results, combined with lithologic considerations, shows that none of these intervals of anomalous inclinations is a likely candidate for an excursion. For example, the event at Hole 821A at 35-38.8 mbsf is reproducible in all the data sets, but coincides precisely with a coarse, low-carbonate layer at the onset of one of the prominent susceptibility peaks (the layer is thought to represent a glacial lowstand). In such variable lithology, it is inappropriate to assign a primary geomagnetic origin to anomalous directions. Barton et al. (this volume) noted that although there is still considerable scatter in the Hole 820 records, some of the broad trends in inclination in the top $120 \mathrm{~m}$ are reproduced in both Holes $820 \mathrm{~A}$ and $820 \mathrm{~B}$, possibly reflecting very long-period secular variation. Inclination scatter in the upper $140 \mathrm{mbsf}$ at Site 820 is noticeably less than in the corresponding interval at Site 821 .

\section{Polarity at Site $\mathbf{8 1 9}$}

Inclination plots for Hole 819A subsample data are shown in Figure 5. The data are selected stable, characteristic directions obtained from detailed progressive demagnetization (S.K. Omarzai, unpubl. data, 1992). Superimposed on the subsample results is a plot of MDF. The record for Hole 819A, though scattered, contains some well-defined reversals of inclination. The work of S.K. Omarzai (unpubl. data, 1992) shows that the main polarity features of the shipboard record are reproduced after careful progressive demagnetization of subsamples and that many of the erratic spikes in the whole-core record (e.g., those around $10 \mathrm{mbsf}$ ) disappear when demagnetized to higher field values. The complete inclination record can be reconciled with both the geomagnetic polarity time scale and the biostratigraphic ages only by invoking either extraordinary variations in sedimentation rates or substantial intervals of normal overprinting. In the AF-cleaned whole-core record above 140 mbsf (partly shown in Fig. 3C), normal inclinations tend to be steeper than the axial dipole inclination and are scattered about the present-day value of $-45^{\circ}$. Below $200 \mathrm{mbsf}$ inclinations are predominantly reversed, but are, again, generally steeper than the axial dipole value. These steep directions are absent from the subsample results (Fig. 5), which indicates that high coercivity $(>150 \mathrm{Oe}$ ) overprints are pervasive. Furthermore, all the normal-inclination intervals below $45 \mathrm{mbsf}$ (except from 54 to $60 \mathrm{mbsf}$, and 113 to $121 \mathrm{mbsf}$ ) coincide with intervals of very low MDF. We therefore suggest that most of the normal inclinations below $45 \mathrm{mbsf}$ are caused by remagnetization, and that the sediments are of late Matuyama age (reverse polarity). The $\mathrm{B} / \mathrm{M}$ boundary is considered to be at about $41 \mathrm{mbsf}$ ( $40.8 \mathrm{mbsf}$ if the whole core inclination record is interpreted literally). Placement of the B/M boundary anywhere below this level makes it difficult to explain the well-defined stable reverse polarity interval from 41 to $46.5 \mathrm{mbsf}$. Two intervals can be considered as possible candidates for the Jaramillo Subchron (0.97-0.91 Ma). The first is from 54 to 60 mbsf, where inclinations are normal with relatively low scatter and MDFs are moderate (in the range 100-150 Oe). This interval may extend downward to $65.5 \mathrm{mbsf}$, but MDFs then drop well below 100 Oe. Below 65.5 mbsf inclinations are stable and reversed. Above 54 mbsf inclinations are erratic, mostly reversed, but MDFs are ex- tremely low ( $20 \mathrm{Oe})$, so it is difficult to fix the upper boundary of the normal interval. The other possible candidate for the Jaramillo Subchron is the interval from 113 to $121 \mathrm{mbsf}$, where normal inclinations with low scatter coincide with moderate MDFs. It is possible that this normal interval extends down to $125 \mathrm{mbsf}$, although wholecore inclinations become more scattered and MDFs become low ( 60 Oe). The first of the two intervals considered (54-60 mbsf, possibly down to $65.5 \mathrm{mbsf}$ ) has the better quality magnetic record and also encompasses WG/0.92 at $56.1 \mathrm{mbsf}$ (Wei and Gartner, this volume). Thus, our preferred interpretation is that the Jaramillo Subchron is represented by the interval 54-65.5 mbsf. No reversal boundaries are identified below $125 \mathrm{mbsf}$ where the intervals of positive inclination are all considered to result from remagnetization during the Brunhes. This is consistent with a biostratigraphic age of $<1.48 \mathrm{Ma}$ at the base of the Hole (Wei and Gartner, this volume).

\section{Polarity at Site 822}

Inclination plots for Hole $822 \mathrm{~A}$ subsample data are shown in Figure 6. Subsample directions are selected stable, characteristic directions obtained from detailed progressive demagnetization (S.K. Omarzai, unpubl. data, 1992). Superimposed on the subsample results is a plot of the MDF. It is apparent that intervals of overprinting are present, although less prevalent than at Sites 819 through 821 . For example, there is a long interval of stable reversed polarity from 195 to $335 \mathrm{mbsf}$. We apply the argument used for Site 821 and treat intervals of low MDF as liable to be partially or completely overprinted. Based on this criterion, and using the calcareous nannofossil ages as a guide, we are fairly confident that the B/M boundary is at $51 \mathrm{mbsf}$ and the Matuyama/Gauss boundary $(2.47 \mathrm{Ma})$ is at $415 \mathrm{mbsf}$. Toward the top of the Matuyama Chron there are two intervals of suspected normal polarity (83-88 and 109-116 mbsf) that are possible candidates for the Jaramillo Subchron (0.91-0.97 Ma). The upper interval fits better with the location of WG/0.92 at $77.8 \mathrm{mbsf}$ (Wei and Gartner, this volume) and is, therefore, tentatively assigned to the Jaramillo Subchron. If this is correct, the lower interval might correspond to the Cobb Mountain Event, although a poor record such as this cannot be expect to record the Cobb. There is a short interval of normal polarity at 193 mbsf of unknown identity. The normal polarity interval from 339 to 360 mbsf would appear to correspond to the Olduvai Subchron, despite being slightly below WG/1.88 (334 mbsf). However, the MDFs are low in this interval, except for the specimen at 344.53 mbsf, so the impression given by Figure 6 that the Olduvai is well-defined is misleading. We tentatively assign an age in the range of $1.66-1.88 \mathrm{Ma}$ at $344.53 \mathrm{mbsf}$.

\section{Polarity at Site 823}

Inclinations are more scattered at Site 823 than at any other site, and there are few, if any, intervals of scattered intermediate directions that could possibly be interpreted as overprinted reversed directions. The scatter increases down to $350 \mathrm{mbsf}$, remaining fairly constant thereafter. In the whole-core record, inclinations tend to be steeper than axial dipole and are scattered about the present-day inclination of $-45^{\circ}$ (Fig. 3E). This present-day component is largely cleaned out in the subsample record and inclinations are scattered about the normal axial dipole direction. MDFs are moderately high (150-300 Oe) in the upper $30 \mathrm{~m}$ of the section, but are consistently low (50-150 Oe) throughout the rest of the sequence and only isolated specimens, or clusters of specimens, have higher values. We conclude that the entire sequence is remagnetized by a present-day VRM and a highcoercivity normal component of either VRM or chemical origin. It is possible that a drilling-induced remanence is responsible for some of the steep inclinations.

Drift of Australia northward will produce a gradual shallowing of the expected axial dipole inclination through time. Estimates of the drift rate range up to about $10 \mathrm{~cm} / \mathrm{yr}$. This corresponds to a rate of 

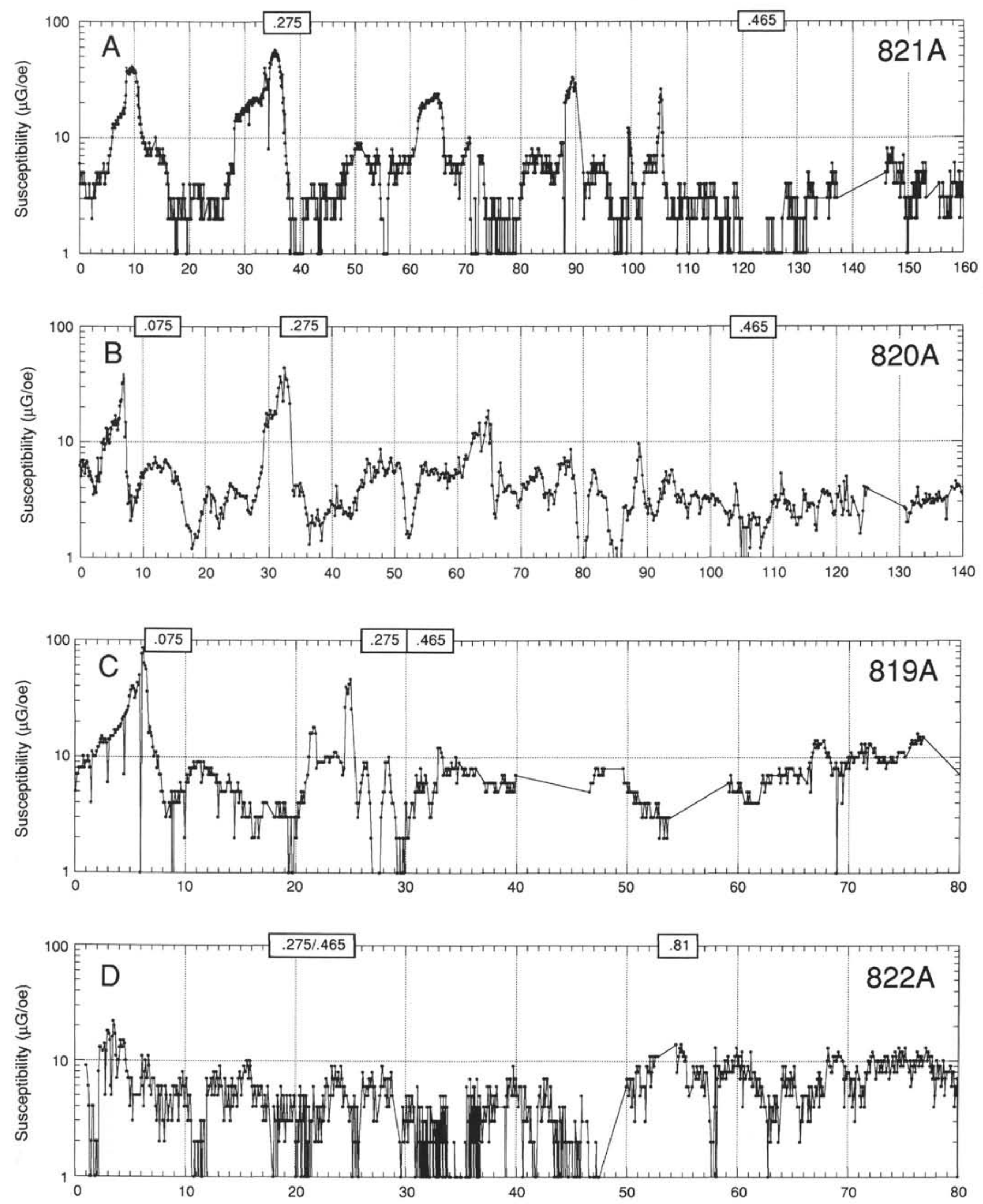

Figure 2. Plots of magnetic susceptibility per unit volume for the upper parts of Sites 819 through 823 . The records for Holes $820 \mathrm{~A}$ and $823 \mathrm{~A}$ are from subsample data; other records are from shipboard whole-core data. In this and subsequent figures, the numbers along the top margins are the calcareous nannofossil age datums of Wei and Gartner (this volume) in units of Ma. 


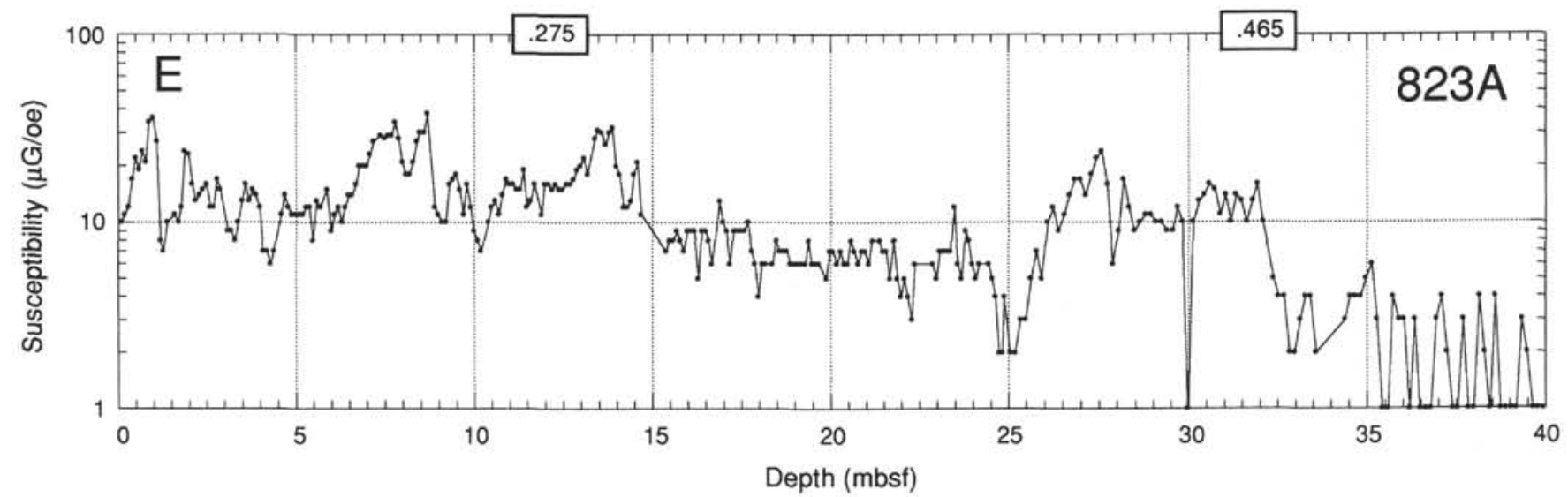

Figure 2 (continued).

change of axial dipole inclination of $1.3 \% \mathrm{~m} . \mathrm{y}$. Thus, the records at Sites 819 through 822 are too short to be used to detect the effects of northward plate movement.

Even at the base of Site 823 (10.4 Ma) the shallowing of axial dipole inclination due to northward drift is only $13.5^{\circ}$. In fact, the inclinations in the lower part of Site 823 are systematically steeper than the axial dipole, typically by $20^{\circ}$. However, this is a feature of virtually the whole sequence and cannot be considered to be of primary geomagnetic origin.

\section{Summary of Reversal Boundaries}

The preferred polarity assignments for each site are summarized in Table 3. No polarity boundaries can be identified at Site 823. The results are consistent with the biostratigraphy of Wei and Gartner (this volume) apart from disagreement at Site 822 between the assigned positions for WG/0.92 and the Jaramillo Subchron, and for WG/1.88 and the Olduvai Subchron (refer to Table 9 for a summary). The paleomagnetic ages are worth considering, but are not sufficiently well established to throw serious doubt on the accuracy of Wei and Gartner's chronology for Site 822 .

\section{ORIGIN OF MAGNETIC INSTABILITY AND OVERPRINTING}

Laboratory measurements of VRM acquisition show that both Sites 820 and 823 suffer from heavy viscous remagnetization, which effectively obliterates the primary magnetization. This must apply equally to Site 821 where, again, there are no well-defined polarity reversals. However, at the mid- and lower-slope sites (Sites 819 and 822 , respectively) a better primary magnetization does appear to be preserved. A partial explanation for these differences can be found in

Table 3. Geomagnetic polarity assignments.

\begin{tabular}{|c|c|c|c|c|c|c|c|}
\hline \multirow[b]{2}{*}{ Boundary } & \multirow{2}{*}{$\begin{array}{l}\text { Age } \\
\text { (Ma) }\end{array}$} & \multicolumn{6}{|c|}{ Hole } \\
\hline & & $821 \mathrm{~A}$ & $820 \mathrm{~A}$ & $820 B$ & $819 A$ & $822 \mathrm{~A}$ & $823 \mathrm{~A}$ \\
\hline Brunhes/Matuyama & 0.73 & $137-155^{a}$ & $126+^{a}$ & $132-143^{a}$ & 40.8 & 51 & - \\
\hline Top of Jaramillo & 0.91 & & & & $54 ?$ & $83 ?$ & - \\
\hline $\begin{array}{l}\text { Bottom of } \\
\text { Jaramillo }\end{array}$ & 0.97 & & & & $65.5 ?$ & $88 ?$ & - \\
\hline Top of Olduvai & 1.66 & & & & & 339 ? & - \\
\hline Bottom of Olduvai & 1.88 & & & & & 360 ? & - \\
\hline Matuyama/Gauss & 2.47 & & & & & 415 & - \\
\hline
\end{tabular}

${ }^{\text {a }} \mathrm{B} / \mathrm{M}$ boundary yrobably lies somewhere in this interval; ? = uncertain assignment ; blank entries signify that the hole did not penetrate as far as the specified boundary; dashes indicate that the specified boundary is not identified. terms of grain-size variation. We expect a systematic decrease in magnetic grain size at increasing distances from coastal sources of terrigenous material because finer particles remain in suspension longer and, therefore, can be transported further. At Site 820 we find a substantial multidomain (MD) fraction that is responsible for the VRM and wipes out the primary remanence signal. We assume this is also the case at Site 821 because of the similarity in the nature of the records. However, farther away from the shore at Sites 819 and 822 the magnetic grain size spectrum shifts toward the pseudo-single domain (PSD) and SD range, giving rise to more stable remanence. This is consistent with the view that the middle and lower slopes are depleted in coarser-grained material that is preferentially deposited on the shelf and upper slope. The "background" sediments at Site 823 (i.e., not in the prominent susceptibility peaks) give an SD-type Lowrie-Fuller test result. Hence, they are unlikely to carry an MD VRM (Barton, this volume) and probably suffer from chemical overprinting. It has been suggested that the absence of a primary paleomagnetic signal at Site 823 might partly be due to physical disturbance caused by the numerous gravity-flow deposits in the sequence. However, this explanation is not entirely satisfactory because there are intervals of quiescent sedimentation between the gravity flows that give equally erratic directions. Furthermore, we might expect that the post-depositional magnetization acquired in settling gravity-flow deposits would produce a stable, unidirectional remanence - there is no evidence for this. Measurements at Site 820 (Barton et al., this volume) indicate that the predominantly MD "background" sediments probably include a fraction of ultrafine grains near the SD/ superparamagnetic (SP) threshold size $(\sim 0.03 \mu \mathrm{m}$; Dunlop, 1973). This fraction would also contribute to the VRM. There is insufficient information currently available to determine whether there is a sitedependence of the SP content of the "background" sediments.

\section{Geochemical Gradients, Sulfate Reduction, and Dissolution}

Strong geochemical gradients occur in the uppermost sediments at all sites (Davies, McKenzie, Palmer-Julson, et al., 1991). These gradients appear to be responsible for the dissolution of primary iron oxides by sulfate reduction (the process and its rock-magnetic effects are described by Karlin and Levi, 1983). The sulfate ion and alkalinity gradients of interstitial waters for each site are shown in Figure 7 (data from Davies, McKenzie, Palmer-Julson, et al., 1991). As the sulfate concentration declines with depth, there is a commensurate increase in alkalinity, as expected. This is accompanied by a downcore decrease in NRM intensity and a pronounced decrease in MDF (Fig. 8) at the top of each sequence that reflect the removal of detrital magnetite. The decrease of MDF is indicative of preferential dissolution of fine grained (SD-sized) detrital magnetite that carries a stable 

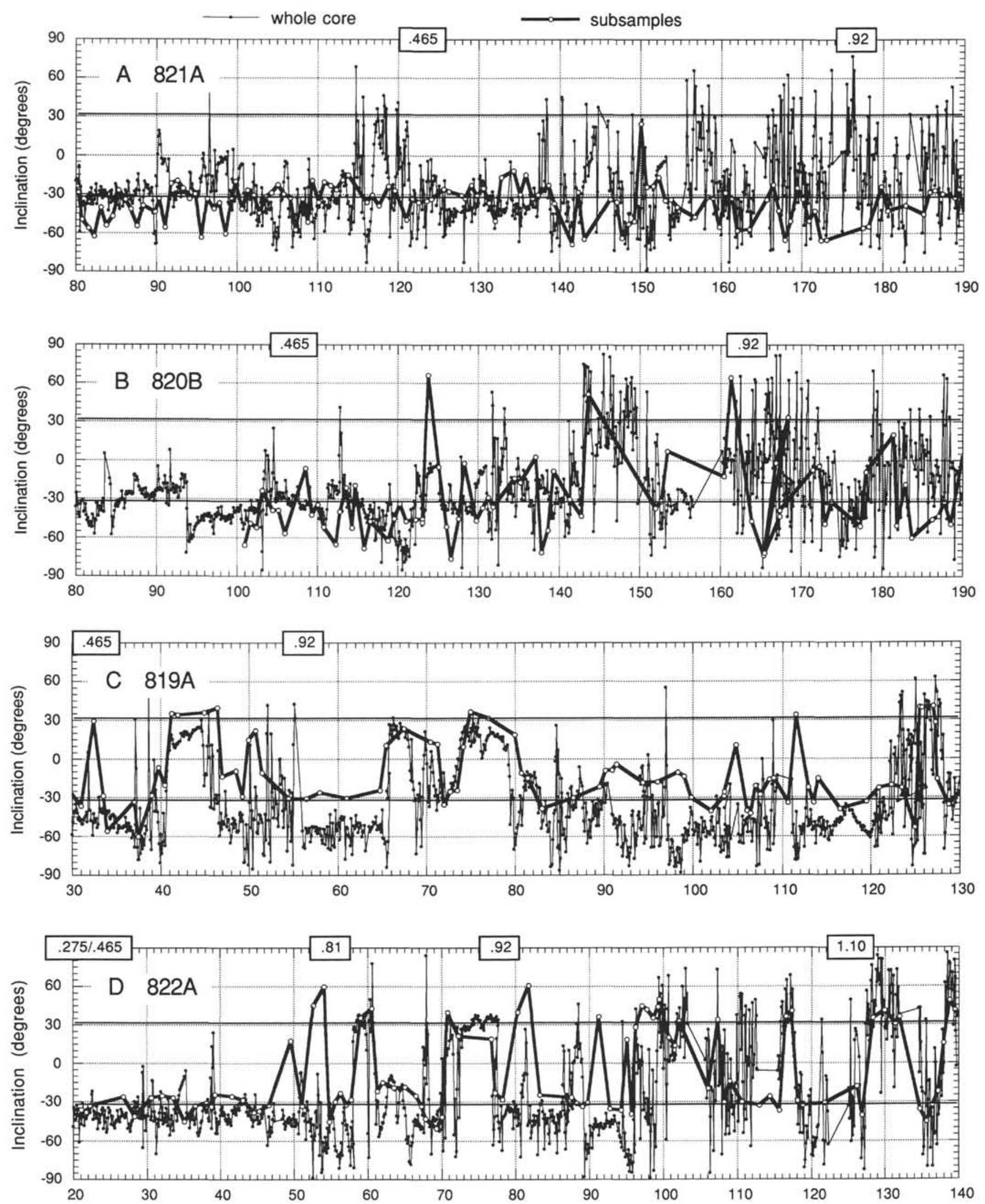

Figure 3. Magnetic inclination records for each site spanning the Brunhes/Matuyama boundary region. Results shown are for both AF-cleaned shipboard data and subsample data. The tram lines are the geocentric axial dipole directions for normal and reversed fields. 


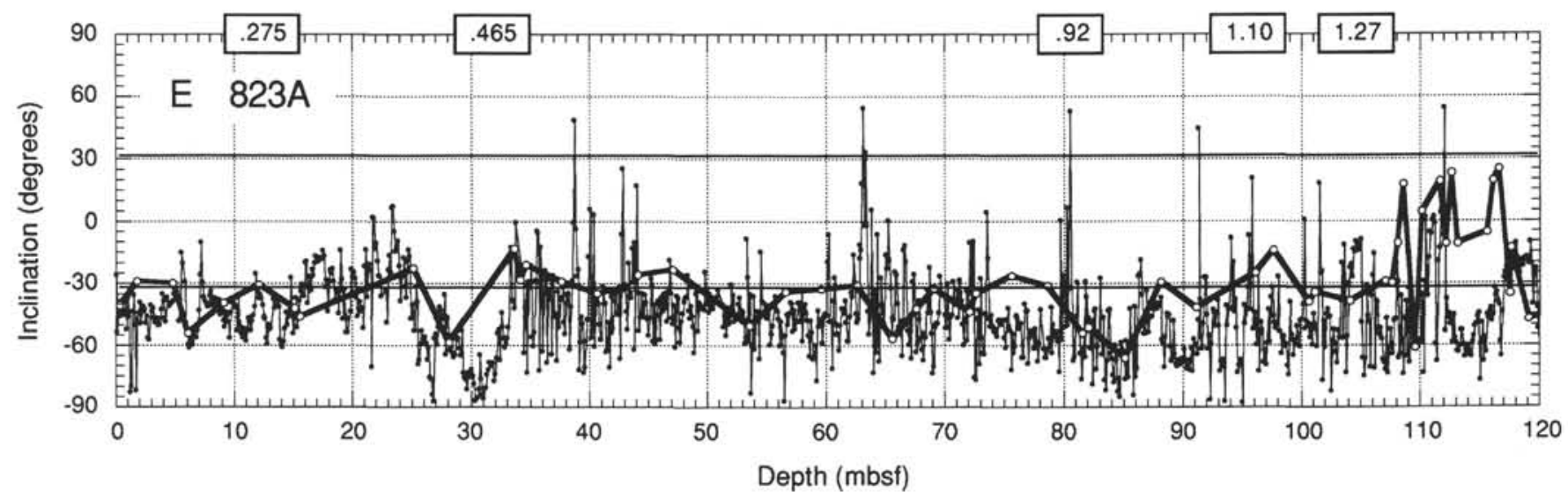

Figure 3 (continued).
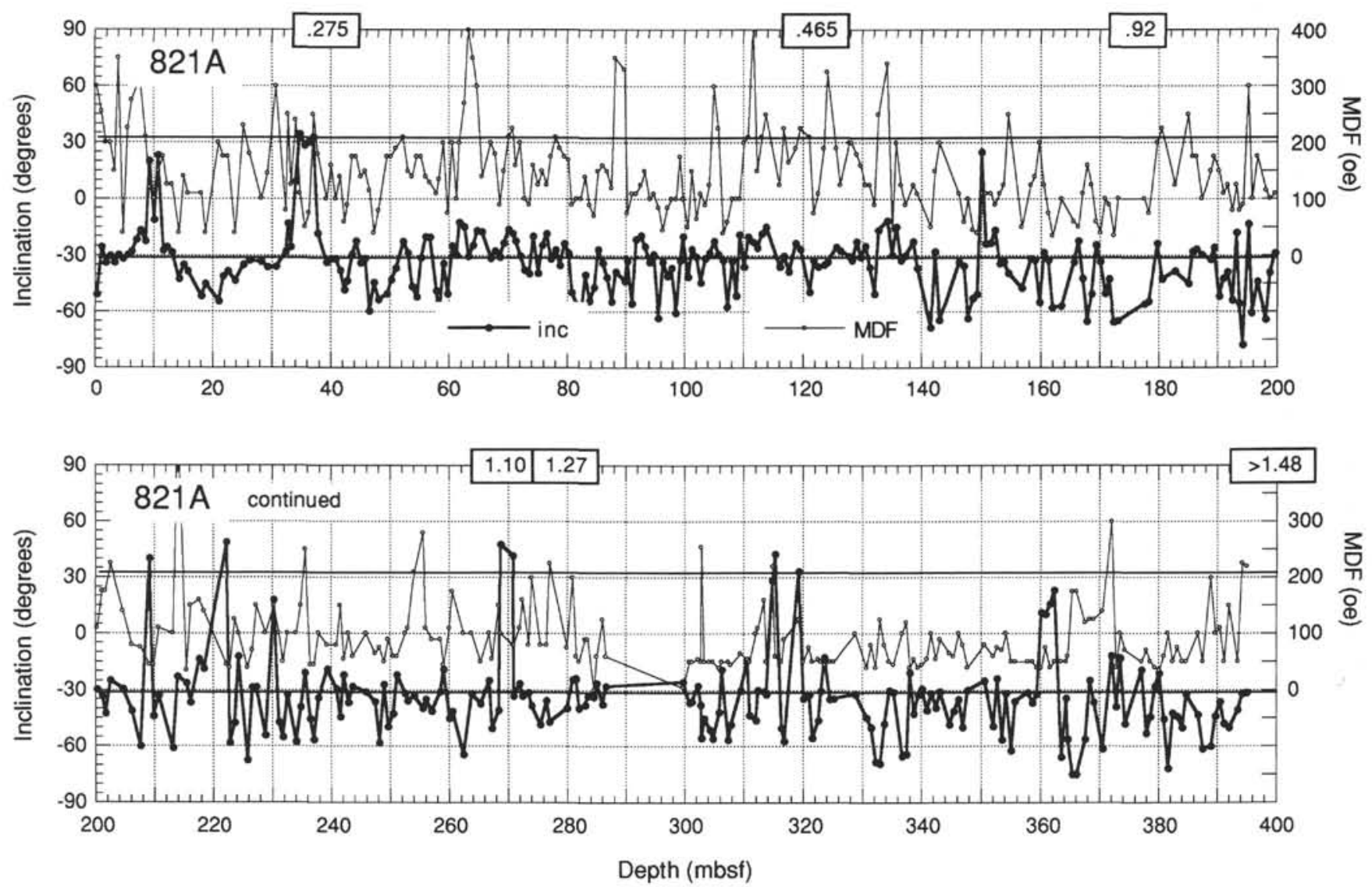

Figure 4. Subsample stable inclination and median destructive field plots for Hole 821A. Data from S.K. Omarzai (unpubl. data, 1992); stable component directions derived from progressive $\mathrm{AF}$ and thermal demagnetization.

remanence, leaving a residual, less-stable MD and, possibly, SP assemblage. The same effect is evident in the Q-ratio plots (Fig. 9), although the picture is less clear and is complicated by the high Q values associated with the last glacial maximum and the ensuing transgression (4-7 mbsf at Site 820 and 5-9 mbsf at Site 821). The question of the iron-sulfide products of sulfate reduction, and their contribution to the magnetic signature of the sediments has not yet been addressed; it is most likely that some of the low-stability magnetization that we have labeled as MD magnetite may reside in iron sulfides. Iron sulfides are certainly present and are noted in several core descriptions. A centimeter-size lump of pyrite has been found at $65.35 \mathrm{mbsf}$ at Hole $820 \mathrm{~A}$.

Alexander et al. (this volume) considered the dissolution of magnetic grains in terrigenous particles the most important factor controlling the overall magnetic signature at Site 819. Alexander et al. noted a sharp, 10-fold downcore decrease in susceptibility and saturation isothermal remanent magnetization (SIRM) at about $7.5 \mathrm{mbsf}$ at Hole $819 \mathrm{~A}$, accompanied by a similarly sharp decrease in the ratio of anhysteretic remanent magnetization (ARM) to specific susceptibility $(X)$ and a decrease from 0.9 to 0.7 of the isothermal remanent 

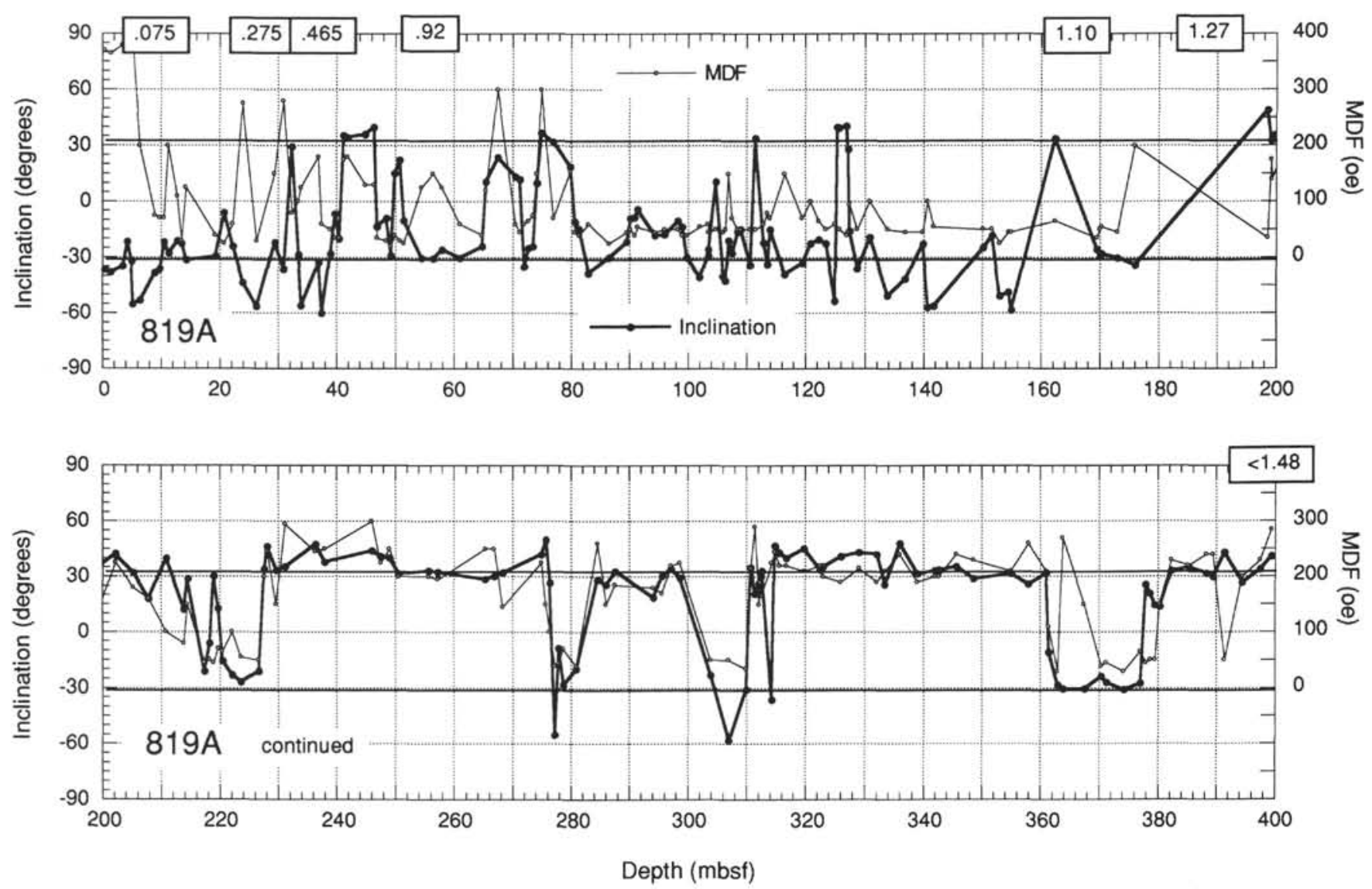

Figure 5. Subsample stable inclination and median destructive field plots for Hole 819A. Data from S.K. Omarzai (unpubl. data, 1992); stable component directions derived from progressive $\mathrm{AF}$ and thermal demagnetization.

magnetization $S$-ratio (defined as $\operatorname{IRM}_{10000} / \mathrm{IRM}_{100000 \mathrm{e}}$ ). They attributed this to dissolution and commented that the $S$-ratio decrease is diagnostic of a change from stable SD-sized grains with diameters of about $0.1 \mu \mathrm{m}$ to large $(>10 \mu \mathrm{m})$ easily magnetized magnetic grains.

The results shown in Figures 7, 8, and 9 provide further insight into intersite differences in magnetic stability. Sites 819 and 822 have the best remanence signals and also the steepest sulfate gradients (reducing-zone depths of 25 and $17 \mathrm{~m}$, respectively). By contrast, Sites 821,820 , and 823 , which have poorer stability and more severe overprinting, have significantly lower sulfate gradients (reducingzone depths of 145,52 , and $42 \mathrm{~m}$, respectively). Dissolution of fine-grained magnetite will be confined largely to the surface zone, where the large geochemical gradients occur. Thus, for a given sedimentation rate, a high geochemical gradient implies a short residence time in the corrosive surface zone, and, hence, a higher probability of surviving dissolution. The converse will apply for low gradients in which the removal of fine-grained magnetite will be more complete.

Differences in sedimentation rate must also be considered, so let us assume that the residence time in the corrosive zone, $T$, is given by

\section{$T=$ depth of surface reducing zone/sedimentation rate.}

The relevant figures for each site are summarized in Table 4. It is apparent that shorter residence times are associated with better preservation of stable remanence carriers (generally fine-grained magnetite). If we assume that the geochemical gradients observed today are typical of the past, then this dissolution mechanism is probably a major factor in determining the magnetic stability characteristics of the sediments and provides an explanation for the differences between sites. If the surface geochemical gradients are sedimentation ratedependent, then $T$ becomes more strongly dependent on the depth of the reducing zone alone, and the argument still holds. Although the dissolution mechanism provides an explanation for between-site differences, we find that it is not sufficient to account for intrasite distributions of magnetic grain sizes within glacial and interglacial cycles in the upper slope sequences. Peerdeman and Davies (this volume) show that during the last glacial maximum the sedimentation rate at Site 820 was at a minimum and that rates gradually increased during the subsequent transgression to relatively high values for the present interglacial highstand. Barton et al. (this volume) report that at Site 820 , the onsets of glacial maxima (marked by sharp peaks in susceptibility) are characterized by SP and SD magnetic properties, the subsequent transgressions are predominantly SD, and the interglacial highstands have largely MD properties. This is contrary to what we would expect from a dissolution mechanism.

Table 4. Residence time in the surface reduction zone.

\begin{tabular}{|c|c|c|c|c|}
\hline Site & $\begin{array}{l}\text { Record } \\
\text { quality }\end{array}$ & $\begin{array}{l}\text { Reducing } \\
\text { zone } \\
\text { depth } \\
\text { (mbsf) }\end{array}$ & $\begin{array}{l}\text { Sedimentation } \\
\text { rate } \\
(\mathrm{m} / \mathrm{m} . \mathrm{y} .)\end{array}$ & $\begin{array}{c}\text { Residence } \\
\text { time } \\
\text { (m.y.) }\end{array}$ \\
\hline 821 & Bad & 145 & 143 & 1.01 \\
\hline 820 & Bad & 52 & 130 & 0.4 \\
\hline 823 & Worst & 42 & 44 & 0.95 \\
\hline 819 & Better & 25 & 107 & 0.23 \\
\hline 822 & Better & 17 & 79 & 0.21 \\
\hline
\end{tabular}

Note: Record quality is judged from directional scatter, stability, and overprintng considerations. 

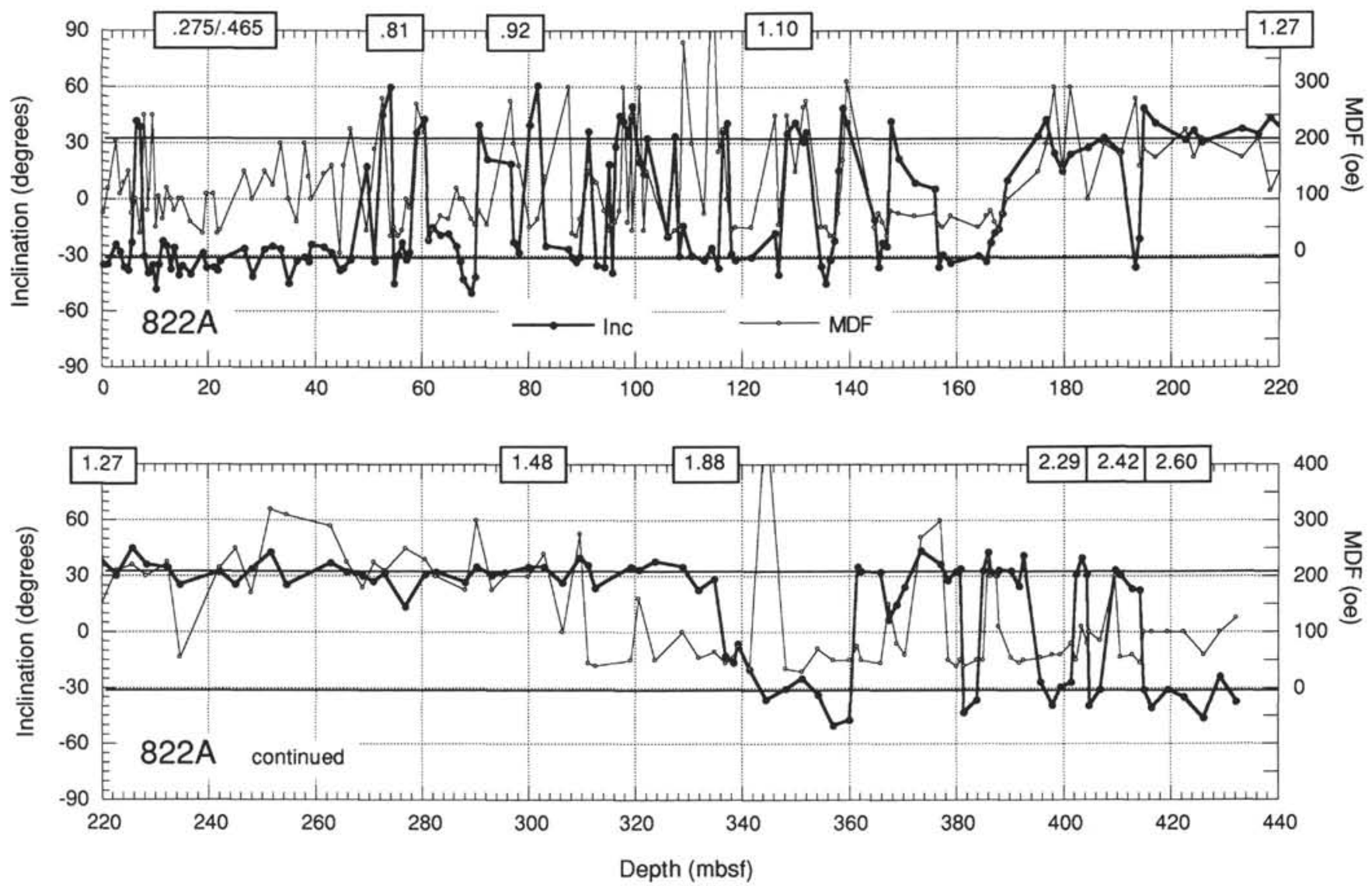

Figure 6. Subsample stable inclination and median destructive field plots for Hole 822A. Data from S.K. Omarzai (unpubl. data, 1992); stable component directions derived from progressive $\mathrm{AF}$ and thermal demagnetization.

Average sedimentation rates in the prograding sequence on the upper slope are many times higher than in the overlying aggrading sequence. The dissolution argument would, therefore, predict that the aggradational, pre-GBR sequence would have a finer grain-size spectrum. Results from Site 820 indicate that this is not the case.

\section{INTERSITE CORRELATION USING SUSCEPTIBILITY}

When using magnetic susceptibility to correlate among sites, we find that Site 820 provides the most satisfactory master record against which to compare records from the other sites. There is sufficient detail in the magnetic susceptibility records to permit accurate correlation between adjacent holes. Barton et al. (this volume) have correlated Holes $820 \mathrm{~A}$ and $820 \mathrm{~B}$ to an accuracy generally within $20 \mathrm{~cm}$, which is sufficient to detect minor irregularities in sediment recovery and sediment accumulation. Between-site correlations are less accurate and incomplete, but contain a wealth of useful information.

\section{Correlation Between Sites 821 and 820}

Seismic sections indicate that the sequences at Sites 821 and 820 are similar, particularly in the aggrading part of the record, and have comparable accumulation rates (Davies, McKenzie, Palmer-Julson, et al., 1991). This is borne out by the biostratigraphic ages of Wei and Gartner (this volume) and by the seismic sequence analysis of Feary et al. (this volume). The magnetic susceptibility records are also similar for the two sites and can be used to fine-tune the chronology. To do this, all available whole-core and subsample susceptibility data were used. Data from Hole 820A were transformed to the depth scale of Hole $820 \mathrm{~B}$ using the correlation scheme proposed by Barton et al. (this volume).

Depths of matching susceptibility features at Sites 821 and 820 , together with the biostratigraphic boundaries, are listed in Table 5. The boundaries between seismic sequences defined by Feary et al. (this volume) are included in the table (denoted by S2/S3, etc.). Whole-core susceptibility logs for the two sites are compared in Figure 10. The biostratigraphic ages and seismic sequence boundaries were used only to provide a general framework for developing the correlation scheme. An effort was made to minimize the relative stretching and compression of the susceptibility records in order to produce an optimum match. This necessitated invoking a hiatus at $72.0 \mathrm{mbsf}$ at Site 820 (corresponding to 70.8-83.2 mbsf at Site 821), and allowing a poor match for two intervals where there are gaps and poor whole-core records: Hole $821 \mathrm{~A}, 120-160 \mathrm{mbsf}$, corresponding to Hole $820 \mathrm{~B}$, 107.1-145.5 mbsf, and Hole 821A, 253-300 mbsf, corresponding to Hole $820 \mathrm{~B}, 248-290.5 \mathrm{mbsf}$. The susceptibility correlation scheme provides a test of the consistency among sites of the biostratigraphy and of the seismic sequence boundary assignments. This is indicated in Table 5 by the equivalent depths in one sequence of a datum in the other sequence based on the susceptibility stratigraphy (numbers in parentheses). Differences are shown in the offset column (note that the offset in one sequence relative to another will generally not be the same as the offset in the other relative to the one). It is clear from the offsets that there is excellent agreement between the magnetic stratigraphy and the calcareous nannofossil ages of Wei and Gartner (this volume). According to the magnetics, WG/0.075 at $12.1 \mathrm{mbsf}$ at Hole 820A(11.6 mbsf at Hole 820B) should occur at $13.5 \mathrm{mbsf}$ at Hole 821 A. 

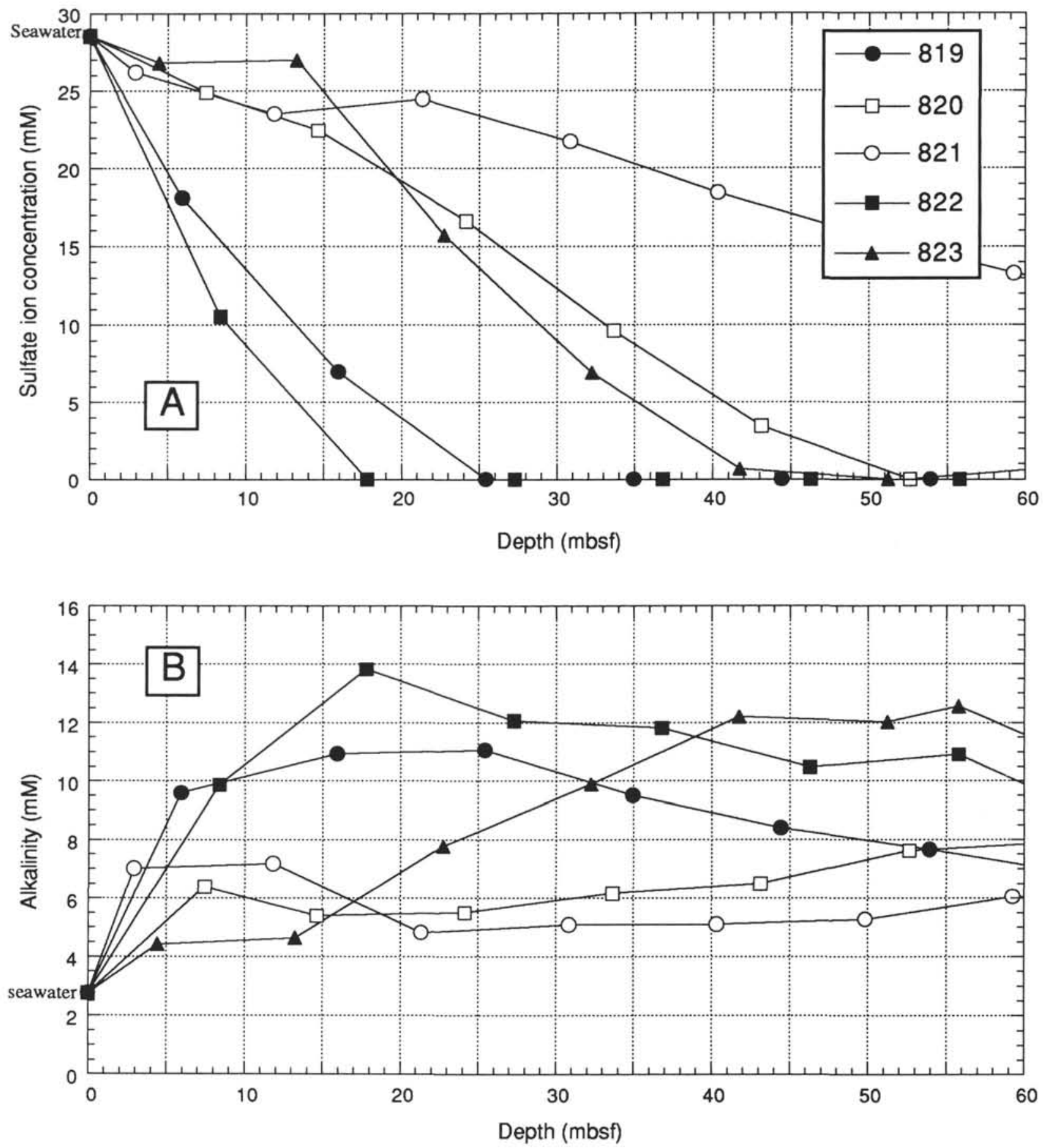

Figure 7. Geochemical gradients in interstitial water from the upper sediments at each site. A. Sulfate ion concentration. B. Alkalinity. Data from Davies, McKenzie, Palmer-Julson, et al. (1991).

There is also excellent agreement for the $\mathrm{S} 2 / \mathrm{S} 3$ and $\mathrm{S} 3 / \mathrm{S} 4$ seismic sequence boundaries, but not for the boundaries below sequence 4 . In fact, the S6/S7 and S7/S8 boundaries at Site 820 appear magnetostratigraphically and susceptostratigraphically equivalent to S7/S8 and S8/S9, respectively, at Site 821 (sequence boundaries as defined by Feary et al., this volume).

The depth intervals at each site in which we think the B/M boundary occurs (see "Magnetic Polarity Stratigraphy" section, this chapter) are also included in Table 5. The lower limits of the range agree well among sites (offset $=-2 \mathrm{~m}$ ), but the upper limit is signifi- cantly higher at Hole $820 \mathrm{~B}$. This implies that the upper limit of the $\mathrm{B} / \mathrm{M}$ range at Site 820 is too high by up to $10 \mathrm{~m}$.

\section{Correlation Between Sites 819 and 820}

Correlation between Sites 819 and 820 is complicated by the hiatuses and slumps at Site 819 , but the two sharp susceptibility peaks at the top of the record clearly match the two peaks at the top of Site 820 and share a similar morphology. A detailed match of the susceptibility records for the upper $25 \mathrm{~m}$ at Hole 819A is illustrated in Figure 


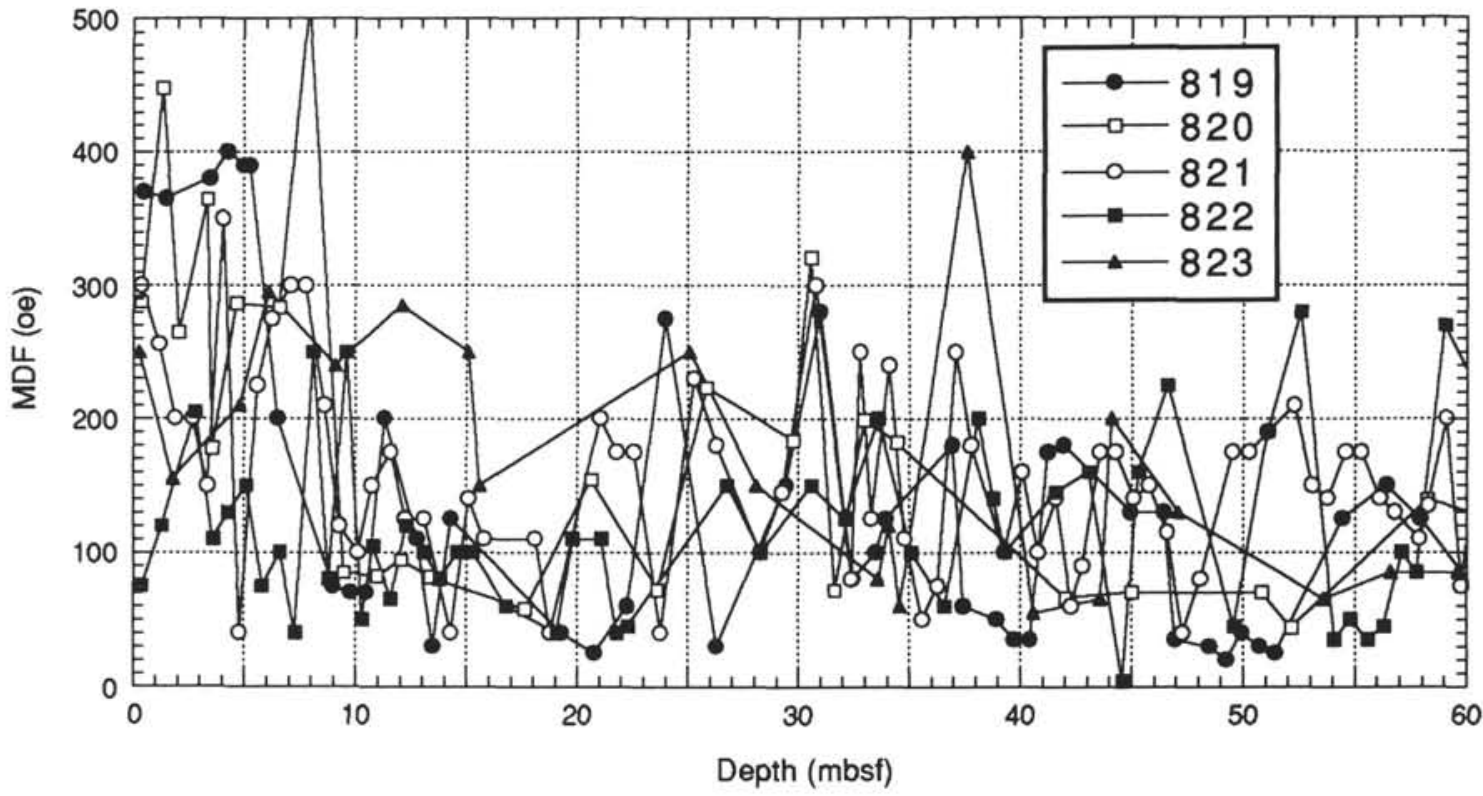

Figure 8. Plots of median destructive field for the upper sediments at each site. Site 820 data from Barton et al. (this volume); other data from S.K. Omarzai (unpubl. data, 1992).

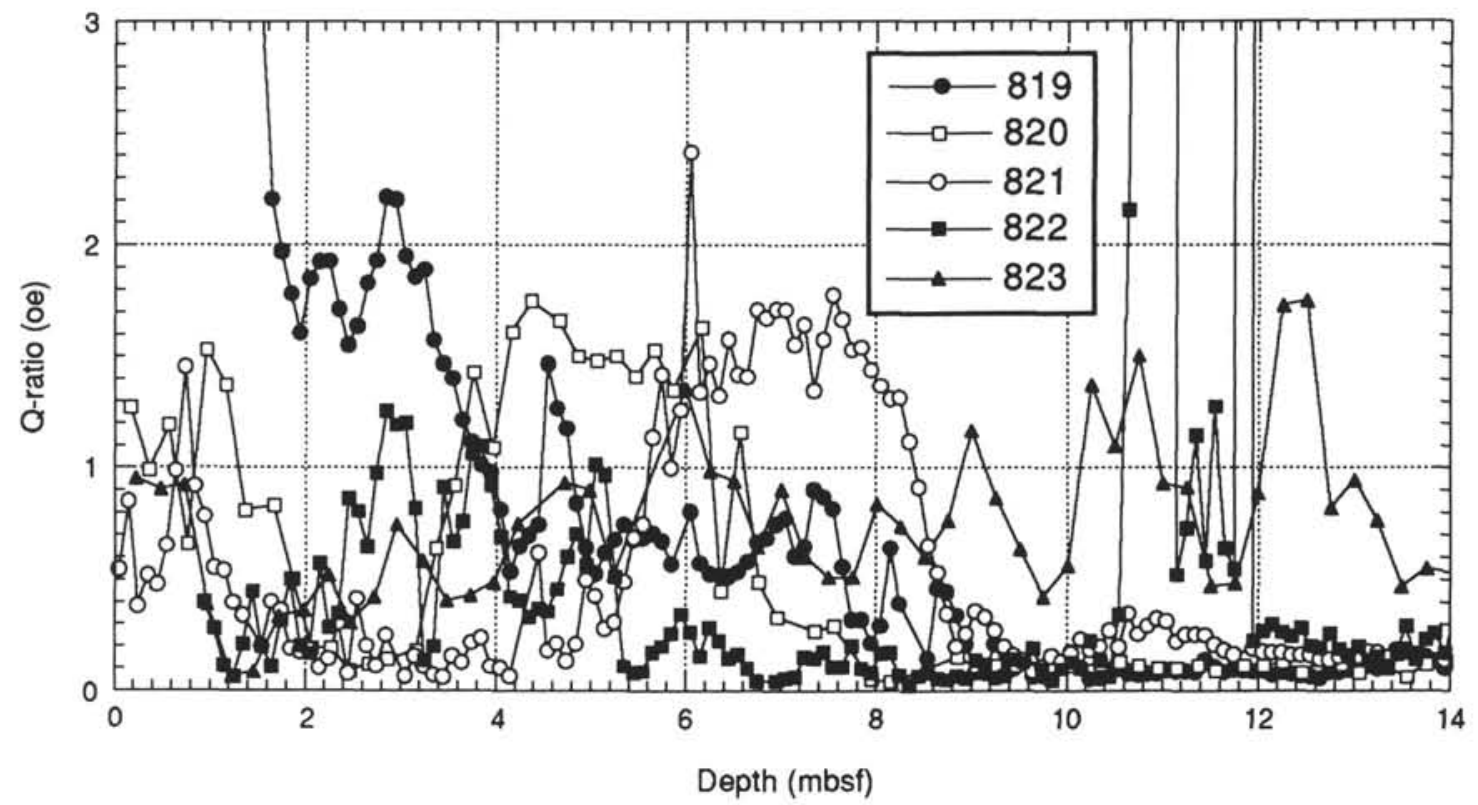

Figure 9. Plots of $Q$-ratio for the uppermost sediments at each site. Site 820 data from subsamples (Barton et al., this volume); other data obtained from shipboard whole-core measurements.

11 (tie points are listed in Table 6). It is clear from the shape of the susceptibility plots that there must be at least one hiatus within the upper $25 \mathrm{~m}$ at Hole $819 \mathrm{~A}$. We have placed this at 19.6 to $20.0 \mathrm{mbsf}$ (corresponding to 22.1-27.9 mbsf at Hole 820A) to match the morphologies of the oxygen isotope records for the two holes (discussed later) as well as susceptibility. Age datums WG/0.075 and WG/0.275 are included in Table 6 . The WG/0.075 and WG/0.275 age datums in Hole $820 \mathrm{~A}$, when transposed to Hole $819 \mathrm{~A}$ using the correlation scheme proposed, come, respectively, $2.6 \mathrm{~m}$ below and $2.2 \mathrm{~m}$ above their counterparts in Hole 819A (as indicated in the final column of Fig. 6). These offsets are relatively small and are within the precision of the biostratigraphy.
There is insufficient resolution in the available susceptibility records to determine whether the interval at Hole 819A between 29.4 $\mathrm{mbsf}$ (WG/0.275) and $32.4 \mathrm{mbsf}$ (WG/0.465) is highly condensed, or whether a hiatus exists. However, the susceptibility record at Hole 819A does appear to be condensed between 29.4 mbsf and the susceptibility minimum at 25.7 mbsf (presumed to mark the onset of minimum sea level).

Below the hiatus at $32.5 \mathrm{mbsf}$ it is less clear how to match the susceptibilities for Holes 819A and 820B. The two susceptibility records agree tolerably well in the vicinity of the WG/0.465 datums (from about 0.42 to $0.58 \mathrm{Ma}$ on a linearly interpolated time scale), suggesting that the placements of this datum in the two holes are consistent. 
Table 5. Susceptibility correlation tie points for Sites 821 and 820 .

\begin{tabular}{|c|c|c|c|c|}
\hline $\begin{array}{l}\text { Tie point } \\
\text { label or } \\
\text { age datum }\end{array}$ & $\begin{array}{l}\text { Depth in } \\
\text { Hole } 821 \mathrm{~A} \\
\text { (mbsf) }\end{array}$ & $\begin{array}{l}\text { Depth in } \\
\text { Hole } 820 \mathrm{~B} \\
\text { (mbsf) }\end{array}$ & $\begin{array}{l}\text { Offset in Hole } 821 \mathrm{~A} \\
\text { relative to Hole } 820 \mathrm{~B} \\
(\mathrm{~m})\end{array}$ & Comment \\
\hline 1 & 2.5 & 2.3 & & \\
\hline 2.0 & 6.1 & 4.3 & & \\
\hline 2 & 9.5 & 7.0 & & \\
\hline WG/0.075 & (13.5) & 11.6 & & \\
\hline 5 & 17.5 & 17.2 & & \\
\hline 6 & 21.5 & 20.5 & & \\
\hline 8.0 & 28.8 & 28.0 & & \\
\hline 8 & 35.5 & 31.4 & & \\
\hline $\mathrm{S} 2 / \mathrm{S} 3$ & $38.0(39.2)$ & $36.0(34.6)$ & -1.2 & \\
\hline WG/0.275 & $39.3(39.3)$ & $35.4(35.4)$ & 0.0 & \\
\hline 9 & 39.5 & 36.4 & & \\
\hline 10 & 50.6 & 46.9 & & \\
\hline 11 & 55.5 & 51.0 & & \\
\hline $\mathrm{C}$ & 56.8 & 53.3 & & \\
\hline 12 & 65.0 & 64.5 & & \\
\hline 13 & 68.3 & 67.8 & & \\
\hline S3/S4 & $69.0(69.0)$ & $70.0(70.0)$ & 0.0 & \\
\hline 14 & 70.8 & 72.0 & & $\begin{array}{l}\text { This interval is missing or condensed in } \\
\text { Hole } 820 \mathrm{~B} \text {. }\end{array}$ \\
\hline 18 & 83.2 & 72.2 & & \\
\hline 19 & 86.0 & 74.9 & & \\
\hline 20 & 89.5 & 77.0 & & \\
\hline 22 & 95.2 & 87.4 & & \\
\hline 23 & 97.2 & 84.3 & & \\
\hline 24 & 99.5 & 87.5 & & \\
\hline 26 & 103.2 & 91.5 & & \\
\hline 29 & 115.7 & 103.2 & & \\
\hline & & & & Records match poorly for Hole $821 \mathrm{~A}$ \\
\hline $\begin{array}{l}\text { WG/0.465 } \\
\text { B/M }\end{array}$ & $\begin{array}{l}123.1(118.8) \\
-137-155(146-157)\end{array}$ & $106.1(110.3)$ & $\sim+4.3$ & \\
\hline $\begin{array}{l}B / M \\
44.4\end{array}$ & $\begin{array}{l}137-155(146-157) \\
160.0\end{array}$ & $\begin{array}{l}132-143(123-141) \\
145.5\end{array}$ & & \\
\hline 46 & 170.8 & 156.1 & & \\
\hline $\mathrm{S} 4 / \mathrm{S} 5$ & $173.5 ?$ & 156.1 & 125 & \\
\hline $34 / \Delta 3$ & $172.0(160.5)$ & $\begin{array}{l}146.0(157.4) \\
155.0 ?\end{array}$ & +12.5 & $\begin{array}{l}\text { First interpretation } \\
\text { Second interpretation }\end{array}$ \\
\hline WG/0.920 & 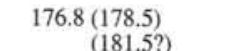 & $\begin{array}{l}163.6(162) \\
(159 ?)\end{array}$ & $\begin{array}{l}-1.7 \\
-4.7\end{array}$ & $\begin{array}{l}\text { First interpretation } \\
\text { Second interpretation }\end{array}$ \\
\hline 48 & 177.5 & 162.7 & & \\
\hline & $181.0 ?$ & 162.7 & & \\
\hline 49 & 183.0 & 166.7 & & \\
\hline 49.5 & 188.5 & 170.0 & & This interval is condensed in Hole $820 \mathrm{~B}$. \\
\hline 50 & 194.5 & 177.0 & & \\
\hline 51 & 196.2 & 181.4 & & \\
\hline 51.5 & 197.7 & 186.1 & & \\
\hline 52 & 213.7 & 202.0 & & \\
\hline 53 & 219.0 & 210.0 & & \\
\hline $\mathrm{S} 5 / \mathrm{S} 6$ & $224.0(217.5)$ & $208.0(215)$ & +6.5 & \\
\hline & & & & $\begin{array}{l}\text { Match is vague for Hole } 821 \mathrm{~A}, 235-300 \\
\text { mbsf (Hole } 820 \mathrm{~B} \text { record incomplete). }\end{array}$ \\
\hline 55.5 & $\sim 253$ & 248.5 & & \\
\hline WG/1.10 & $\sim 270.1(264)$ & $260.3(\sim 266)$ & $\sim+6$ & \\
\hline S6/S7 & $\sim 271.0(290-295)$ & $285.0(\sim 268)$ & $\sim 20$ to -25 & \\
\hline WG/1.27 & $\sim 279.2(277)$ & $271.7(\sim 275)$ & $\sim+2.2$ & \\
\hline $57 / 58$ & $\sim 294.0(321)$ & $311.0(\sim 284)$ & $\sim-27$ & \\
\hline 56 & $\sim 259.0$ & 262.0 & & \\
\hline 57 & $\sim 262.0$ & 265.0 & & \\
\hline 59 & 301.0 & 291.0 & & \\
\hline 60 & 318.0 & 305.5 & & \\
\hline S8/S9 & $319.0(365)$ & $357.0(308)$ & -46 & \\
\hline 61 & 337.0 & 329.0 & & \\
\hline 64 & 361.0 & 352.0 & & \\
\hline 65 & 372.0 & 365.0 & & \\
\hline
\end{tabular}

Note: Tie points are based on matching susceptibility features; B/M = suspected Brunhes/Matuyama boundary interval; S2/S3, etc., are the seismic sequence boundaries defined by Feary et al. (this volume); WG biostratigraphic age boundaries are from Wei and Gartner (this volume), converted from Hole $820 \mathrm{~A}$ to Hole $820 \mathrm{~B}$ where appropriate; ? = second interpretation (first interpretation is preferred); figures in parentheses are equivalent depths at one site of the age datum at the other site.

Below this level, a tentative susceptibility match between Holes $819 \mathrm{~A}$ and $820 \mathrm{~B}$ is possible down to $95 \mathrm{mbsf}$ (tie points are listed in Table 6). However, there are difficulties in matching the records in this inter$\mathrm{val}$, so the correlation scheme given must be treated with caution. The scheme invokes a hiatus (or condensed section) between tie points 48 and 51 . Based on this scheme, the B/M boundary at Hole 819A (at $40.8 \mathrm{mbsf}$ ) has an equivalent depth of $136 \mathrm{mbsf}$ at Hole 820B, which lies within a few meters of other estimates of this boundary.
Correspondence between the positions of WG/0.92 at the two sites is less satisfactory. WG/0.92 at Hole $820 \mathrm{~B}$ corresponds to a depth of $77 \mathrm{mbsf}$ at Hole 819A, which is $20.9 \mathrm{~m}$ above WG/0.92 at Hole 819A; the reverse correspondence gives an offset $13.6 \mathrm{~m}$. The location of WG/0.92 at Hole $820 \mathrm{~B}$ is supported by correlations with other sites, yet WG/0.92 at Hole $819 \mathrm{~A}$ is in excellent agreement with our best (tentative) estimate of the position of the Jaramillo Subchron at Hole $819 \mathrm{~A}$. This problem remains unresolved at present. Certainly the sus- 


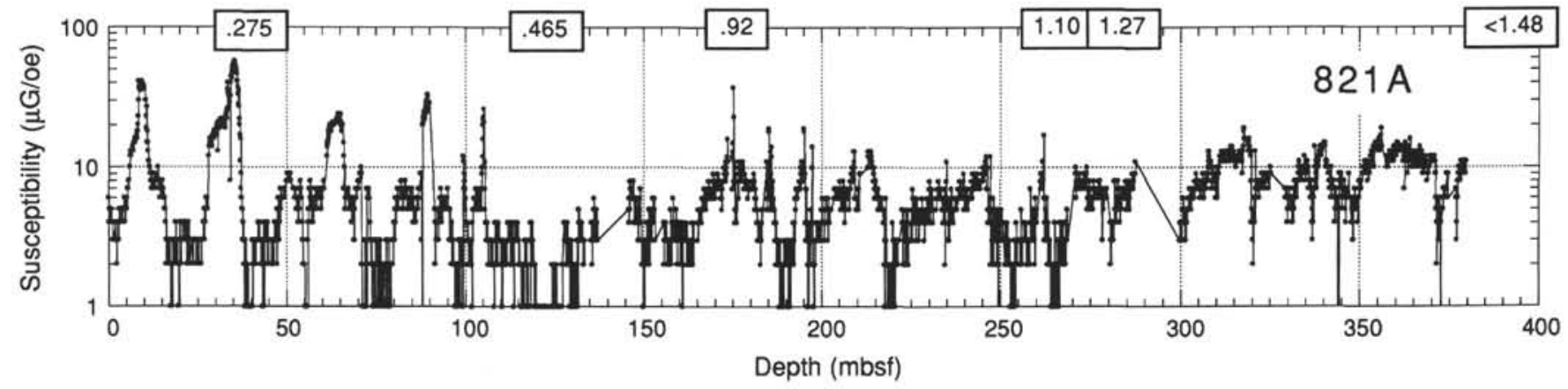

B

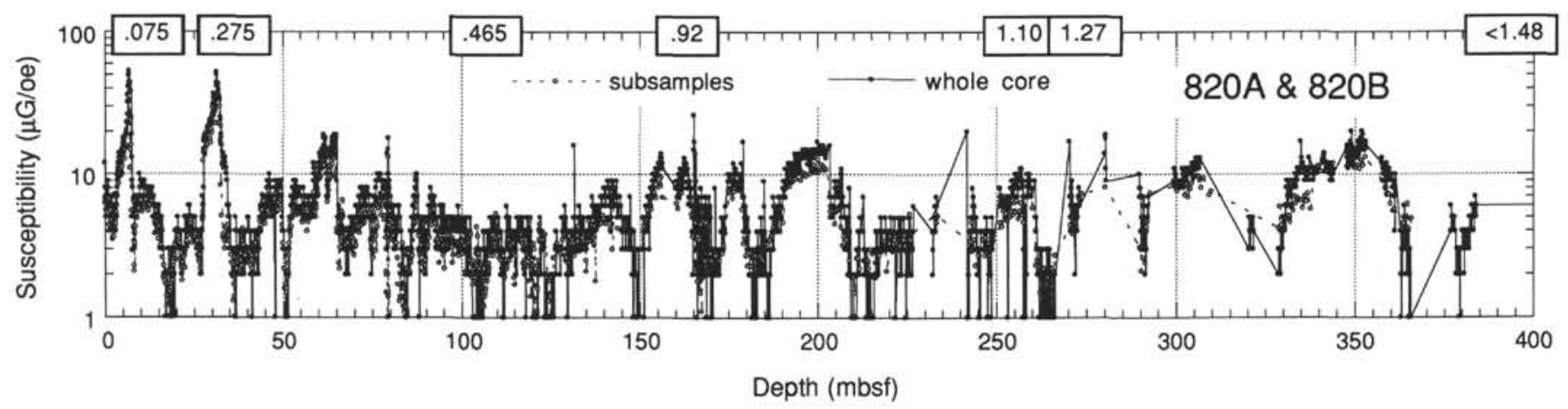

Figure 10. Comparison of magnetic susceptibility records. A. Hole 821A, shipboard whole-core data. B. Site 820, combined shipboard data for Hole $820 \mathrm{~B}$ and subsample data from Holes $820 \mathrm{~A}$ and $820 \mathrm{~B}$. Hole $820 \mathrm{~A}$ data scaled to Hole $820 \mathrm{~B}$ depths using the susceptibility correlation scheme of Barton et al. (this volume).

Table 6. Susceptibility correlation tie points at the top of Sites 819 and 820 .

\begin{tabular}{|c|c|c|c|c|}
\hline $\begin{array}{c}\text { Tie point } \\
\text { label/age } \\
\text { datum }\end{array}$ & $\begin{array}{l}\text { Depth in } \\
\text { Hole 819A } \\
\text { (mbsf) }\end{array}$ & $\begin{array}{l}\text { Depth in } \\
\text { Hole } 820 \mathrm{~A} \\
\text { (mbsf) }\end{array}$ & $\begin{array}{l}\text { Depth in } \\
\text { Hole } 820 \\
\text { (mbsf) }\end{array}$ & $\begin{array}{l}\text { Offset in Hole } 819 \mathrm{~A} \\
\text { relative to Hole } 820 \mathrm{~A} \\
\text { or Hole } 820 \mathrm{~B} \\
\text { (m) }\end{array}$ \\
\hline & 1.8 & 2.1 & 2.4 & \\
\hline & 5.2 & 5.7 & 5.4 & \\
\hline 2 & 6.1 & 7.0 & 6.9 & \\
\hline 3 & 7.8 & 8.0 & 8.3 & \\
\hline WG/0.075 & $8.4(11.0)$ & $12.1(9.0)$ & 11.6 & -2.6 \\
\hline & $16.0(1.0)$ & 17.9 & 17.5 & \\
\hline \multirow[t]{3}{*}{5.5} & 19.6 & 22.1 & 21.7 & \\
\hline & Condensed & & & \\
\hline & 20.0 & 27.9 & 27.1 & \\
\hline 8.0 & 21.5 & 29.8 & 28.5 & \\
\hline \multirow{2}{*}{8} & 24.9 & 33.0 & 31.8 & \\
\hline & 27.1 & 36.5 & 36.3 & \\
\hline WG/0.275 & $29.4(27.2)$ & 35.8 & 35.4 & +2.2 \\
\hline Hiatus & & & & \\
\hline $\mathrm{B} / \mathrm{M}$ & 40.8 & $-(138.4)$ & $-(136)$ & \\
\hline 44 & $48.0 ?$ & & & \\
\hline 45 & $54.0 ?$ & & 149.0 & \\
\hline Upr.Jar & 54.0 & & - (148) & \\
\hline WG/0.92 & $56.1(77.0 ?)$ & & $163.6(150 ?)$ & $-20.9 ?$ \\
\hline Lwr.Jar & & & - (154) & \\
\hline & $67.5 ?$ & & 156.1 & \\
\hline 48 & $76.0 ?$ & & 162.7 & \\
\hline 51 & $80.5 ?$ & & 181.4 & \\
\hline 51.5 & $84.0 ?$ & & 186.1 & \\
\hline 52 & $94.0 ?$ & & 202.0 & \\
\hline
\end{tabular}

Note: Tie points are based on matching susceptibility features; WG biostratigraphic age boundaries are from Wei and Gartner (this volume); figures in parentheses are equivalent depths at one site of the age datum at the other site; ? denotes uncertain correlation; dashes indicate boundaries that are not identifiable. ceptibility logs at the two holes are not compatible with the stated positions of the $0.92 \mathrm{Ma}$ datums, and a minimum offset of $7 \mathrm{~m}$ is required to obtain a match between the immediately adjacent susceptibility features.

Our estimated position of the Jaramillo Subchron at Hole 819A (at 54-65.5 mbsf) corresponds to the interval from 148 to $154 \mathrm{mbsf}$ at Hole 820B, based on the given susceptibility correlations. This lies significantly above Wei and Gartner's (this volume) position for WG/0.92 at 163.6 mbsf.

Below $100 \mathrm{mbsf}$, the match of the susceptibility records between the two holes is equivocal, and no features stand out as being correlated unambiguously.

\section{Correlation Between Sites 822 and 820}

Site 822 is relatively remote $(\sim 25 \mathrm{~km})$ from Sites 821 through 819 and lies at the lower part of the shelf ( $955 \mathrm{~m}$ water depth). As a consequence, there is no obvious susceptibility correlation with the upper slope sequences over most of the record. No prominent sharp susceptibility peaks occur near the top of the record (although higher values occur at 2-4.5 mbsf) and no correlation with the upper slope sites based on susceptibility features is possible down to the hiatus at $21.8 \mathrm{mbsf}$ (where WG/0.275 and WG/0.465 are co-located).

The susceptibility record at Hole $822 \mathrm{~A}$ from 50.0 to $91.7 \mathrm{mbsf}$ can be correlated with a reasonable degree of confidence with that in Hole $820 \mathrm{~B}$ from 138.0 to $180.0 \mathrm{mbsf}$ (Fig. 12). This interval is essentially defined by WG/0.465 and WG/0.92, between which sedimentation rates at the two sites are similar. The relevant tie-points for the correlation are listed in Table 7, using the same labeling system as for the Site $820 / 821$ correlation. WG/0.92 at Sites 820 and 822 are essentially 

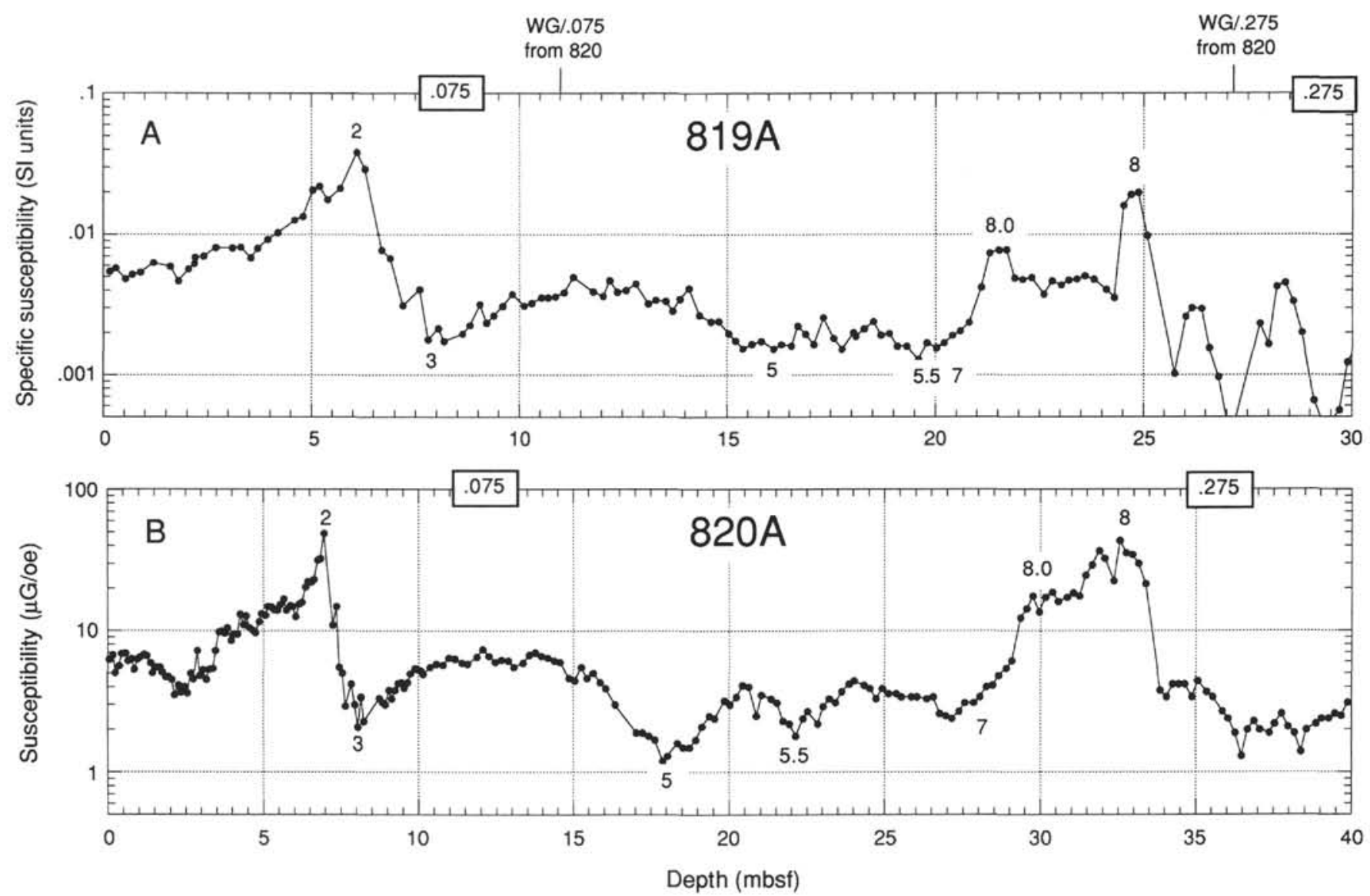

Figure 11. Comparison of magnetic susceptibility records for the upper parts of (A) Hole 819A, specific susceptibility data from Alexander et al. (this volume) and (B) Hole 820A, volume susceptibility data from Barton et al. (this volume). The morphology of the specific susceptibility subsample record illustrated here is almost identical to the shipboard whole-core volume susceptibility record after removal of erratic spikes. Tie-point numbers of matching features are marked on the figure (as listed in Table 6). The susceptibility record for Hole 820B corresponds to that for Hole 820A, apart from minor differences in the depth scales (Barton et al., this volume).

at the same magnetostratigraphic and susceptostratigraphic levels (offset $\sim 1.0 \mathrm{~m}$ ).

Cyclic oscillations in susceptibility occur below $92 \mathrm{mbsf}$ at Site 822 , but there appears to be no meaningful correlation with Site 820 or with Site 819 . For example, the broad susceptibility bulge at 185 to $210 \mathrm{mbsf}$ at Hole $820 \mathrm{~B}$ does not appear in the Hole 822A record.

\section{Correlation Between Sites 823 and 820}

Correlation with Site 823 is complicated by the high incidence of gravity-flow deposits and the different sedimentary regime at the bottom of the trough. It is therefore not surprising that intersite correlations with Site 823 are not possible below $30 \mathrm{mbsf}$. Also, there are features in the susceptibility record for Site 823 that do not appear to have counterparts at the other sites, e.g., the prominent sharp peak in Hole $823 \mathrm{~A}$ at 87 to $88 \mathrm{mbsf}$ (peak 7 in the nomenclature of Figure 6 of Barton, this volume).

Susceptibility records for the upper parts of Holes 823A and 820B are shown in Figure 13, where the numbers on peaks and troughs denote tie points. The interval from $\mathrm{F} 6$ to $24.5 \mathrm{~m}$ in Hole $823 \mathrm{~A}$ contains slump and debris-flow deposits and has been removed from the record illustrated. The sharp susceptibility peaks have similar magnetic properties to the peaks in the aggradational sequences of the upper slope sites (Barton, this volume). The peaks, therefore, probably represent lowstands and early transgressions. The abrupt change in magnetic properties at $32 \mathrm{mbsf}$ (Barton, this volume) and the morphology of the susceptibility record above and below this boundary indicate strongly that there is a hiatus at $32 \mathrm{mbsf}$. Thus, the sediments just above WG/0.465 could be much younger than $0.465 \mathrm{Ma}$.

The Site 823 record contains five main peaks with susceptibilities above $10 \mu \mathrm{G} / \mathrm{Oe}$ (tie points $2,8,10,12.0$, and 12), whereas the Hole $820 \mathrm{~B}$ record contains only three (tie points 2,8 , and 12 ). Thus, it is

Table 7. Susceptibility correlation tie points for Sites $\mathbf{8 2 2}$ and 820.

\begin{tabular}{|c|c|c|c|}
\hline $\begin{array}{l}\text { Tie point } \\
\text { label/age } \\
\text { datum }\end{array}$ & $\begin{array}{l}\text { Depth in } \\
\text { Hole } 822 \mathrm{~A} \\
\text { (mbsf) }\end{array}$ & $\begin{array}{l}\text { Depth in } \\
\text { Hole } 820 \\
\text { (mbsf) }\end{array}$ & $\begin{array}{l}\text { Offset in Hole } 822 \mathrm{~A} \\
\text { relative to Hole } 820 \mathrm{~B} \\
(\mathrm{~m})\end{array}$ \\
\hline $\mathrm{B} / \mathrm{M}$ & 51.0 & $132-143$ (137) & Lies within range \\
\hline WG/0.81 & 54.8 & (141) & \\
\hline 44 & 55.0 & 141.3 & \\
\hline 45 & 62.9 & 149.0 & \\
\hline 46 & 69.1 & 156.1 & \\
\hline 48 & 76.2 & 162.7 & \\
\hline WG/0.92 & $77.8(77.0)$ & $(164.3)$ & +0.8 \\
\hline 50 & 90.3 & 177.0 & \\
\hline
\end{tabular}

Note: Tie points are based on matching susceptibility features; WG biostratigraphic age boundaries are from Wei and Gartner (this volume); figures in parentheses are equivalent depths at one site of the age datum at the other site. 

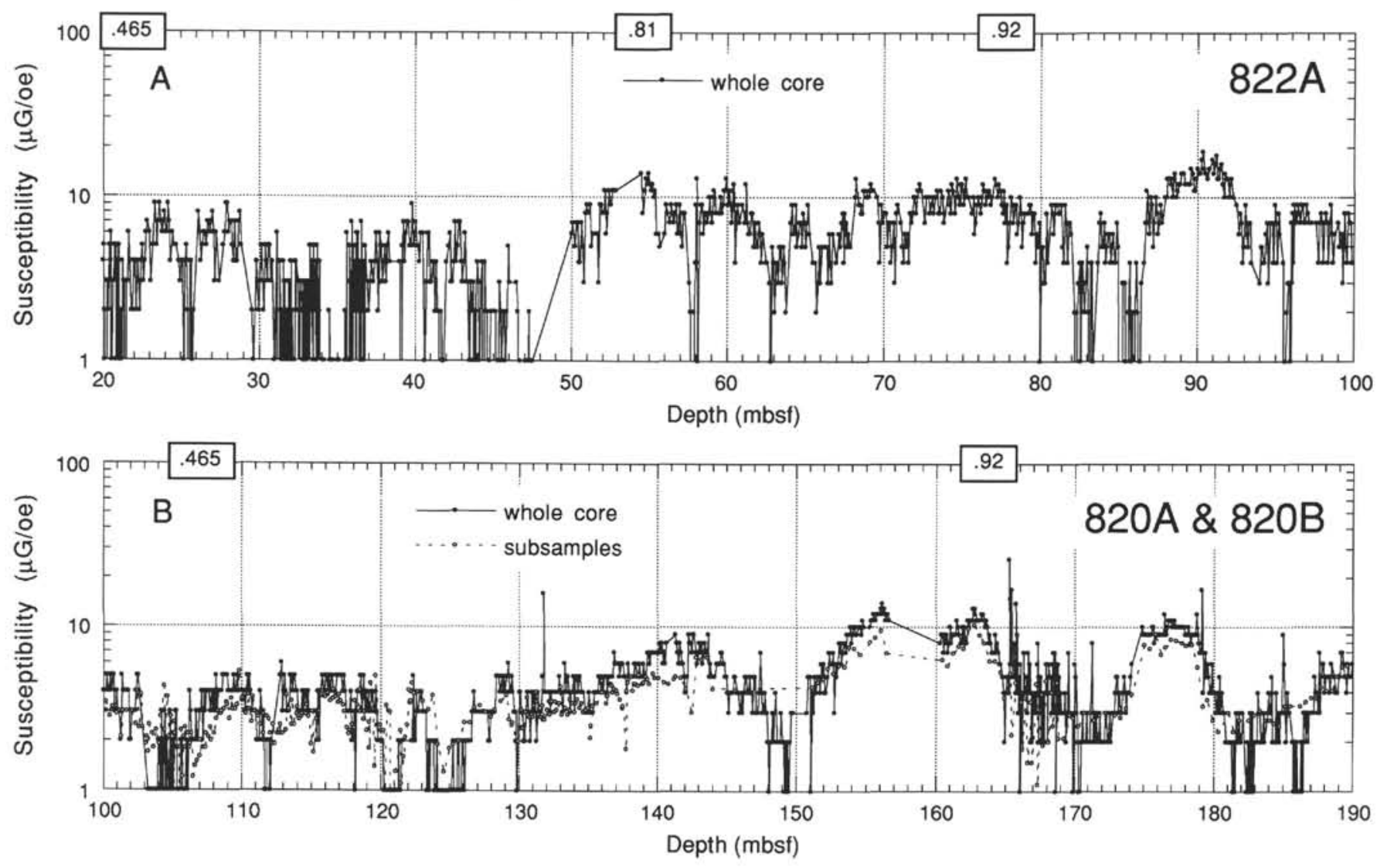

Figure 12. Comparison of susceptibility records in the vicinity of the B/M boundary. A. Hole $822 \mathrm{~A}$. B. Site 820 . Corresponding tie points are listed in Table 7 . Whole-core and subsample data for Holes 820A and 820B are combined and plotted on the depth scale for Hole 820B.

not immediately obvious how the records correlate, if at all. However, if we accept some variability in the relative amplitudes among sites, then it is possible to relate not only all the main peaks and troughs in the two records, but also the minor ones, as well. The tie points are listed in Table 8 and are consistent with the biostratigraphy. If we deem that the relative amplitudes of the main peaks are preserved, then the peak at tie point 10 at Site 823 would have to correspond to the peak at tie point 12 at Site 820. In view of the consistency of the biostratigraphy already established, this seems less probable than the proposed scheme. Using the proposed susceptibility correlation, WG/ 0.075 at Hole $820 \mathrm{~B}$ corresponds to $2.0 \mathrm{mbsf}$ at Hole $823 \mathrm{~A}$, and WG/0.275 at Hole $820 \mathrm{~B}$ corresponds to $9.8 \mathrm{mbsf}$ at Hole $823 \mathrm{~A}$, i.e., $2.4 \mathrm{~m}$ above the level assigned by Wei and Gartner (this volume).

\section{A REVISED MAGNETO-BIOSTRATIGRAPHIC CHRONOLOGY}

Starting with Wei and Gartner's (this volume) calcareous nannofossil chronology, and the available few reversal boundaries, we can develop a revised chronology based on the intersite magnetic susceptibility stratigraphy. This involves addition of the identified reversal boundaries, their inferred positions at other sites, and adjustment of Wei and Gartner's biostratigraphic boundaries to optimize inter-site agreement between susceptibility records.

According to the susceptibility correlation schemes defined in Tables 6 and 7, the B/M boundary placements at Holes 819A at 40.8 mbsf and $822 \mathrm{~A}$ at $51 \mathrm{mbsf}$ are stratigraphically equivalent to 136 and $137 \mathrm{mbsf}$ at Hole $820 \mathrm{~B}$, respectively. These estimates lie in the middle of the 132-143 mbsf range assigned to the boundary at Hole 820B. This agreement is encouraging, and lends credence to our speculations. We adopt $137 \mathrm{mbsf}$ as the preferred position of the $\mathrm{B} / \mathrm{M}$ boundary at Hole $820 \mathrm{~B}$. Using the established susceptibility stratigraphies, this puts the B/M boundary at about $139.5 \mathrm{mbsf}$ at Hole $820 \mathrm{~A}$ and $151 \mathrm{mbsf}$ at Hole $821 \mathrm{~A}$. The B/M boundary at $51 \mathrm{mbsf}$ at Hole $822 \mathrm{~A}$ coincides with an abrupt drop in susceptibility (susceptibility tends to be reduced in the upper half of the interval from WG/0.92 to WG/0.465 at all sites). This has a counterpart in the vicinity of 70 mbsf at Site 823, which is therefore the most likely location of the $\mathrm{B} / \mathrm{M}$ boundary.

Table 8. Correlation tie points for Sites 823 and 820.

\begin{tabular}{|c|c|c|c|}
\hline $\begin{array}{l}\text { Tie point } \\
\text { label }\end{array}$ & $\begin{array}{c}\text { Depth in } \\
\text { Hole 823A } \\
\text { (mbsf) }\end{array}$ & $\begin{array}{l}\text { Depth in } \\
\text { Hole } 820 \mathrm{~B} \\
\text { (mbsf) }\end{array}$ & $\begin{array}{l}\text { Offset in Hole } 823 \mathrm{~A} \\
\text { relative to Hole } 820 \mathrm{~B} \\
\text { (m) }\end{array}$ \\
\hline 2 & 0.9 & 7.0 & \\
\hline 3 & 1.5 & 8.2 & \\
\hline WG/0.075 & (2.0) & 11.6 & \\
\hline & 2.2 & 12.0 & \\
\hline 5 & 3.0 & 17.2 & \\
\hline 5.5 & 4.3 & 21.8 & \\
\hline 7 & 6.0 & 26.9 & \\
\hline 8.0 & 7.4 & 28.0 & \\
\hline 8 & 8.7 & 31.4 & \\
\hline 9 & 10.2 & 36.4 & \\
\hline WG/0.275 & $12.2(9.8)$ & $35.4(42.0)$ & +2.4 \\
\hline 10 & 13.5 & 46.9 & \\
\hline 11 & 25.0 & 51.0 & \\
\hline 12.0 & 27.5 & 53.4 & \\
\hline 12.2 & 30.6 & 61.9 & \\
\hline 12 & 31.9 & 64.5 & \\
\hline
\end{tabular}

Note: Tie points are based on matching susceptibility features; WG biostratigraphic age boundaries are from Wei and Gartner (this volume); figures in parentheses are equivalent depths at one site of the age datum at the other site. 

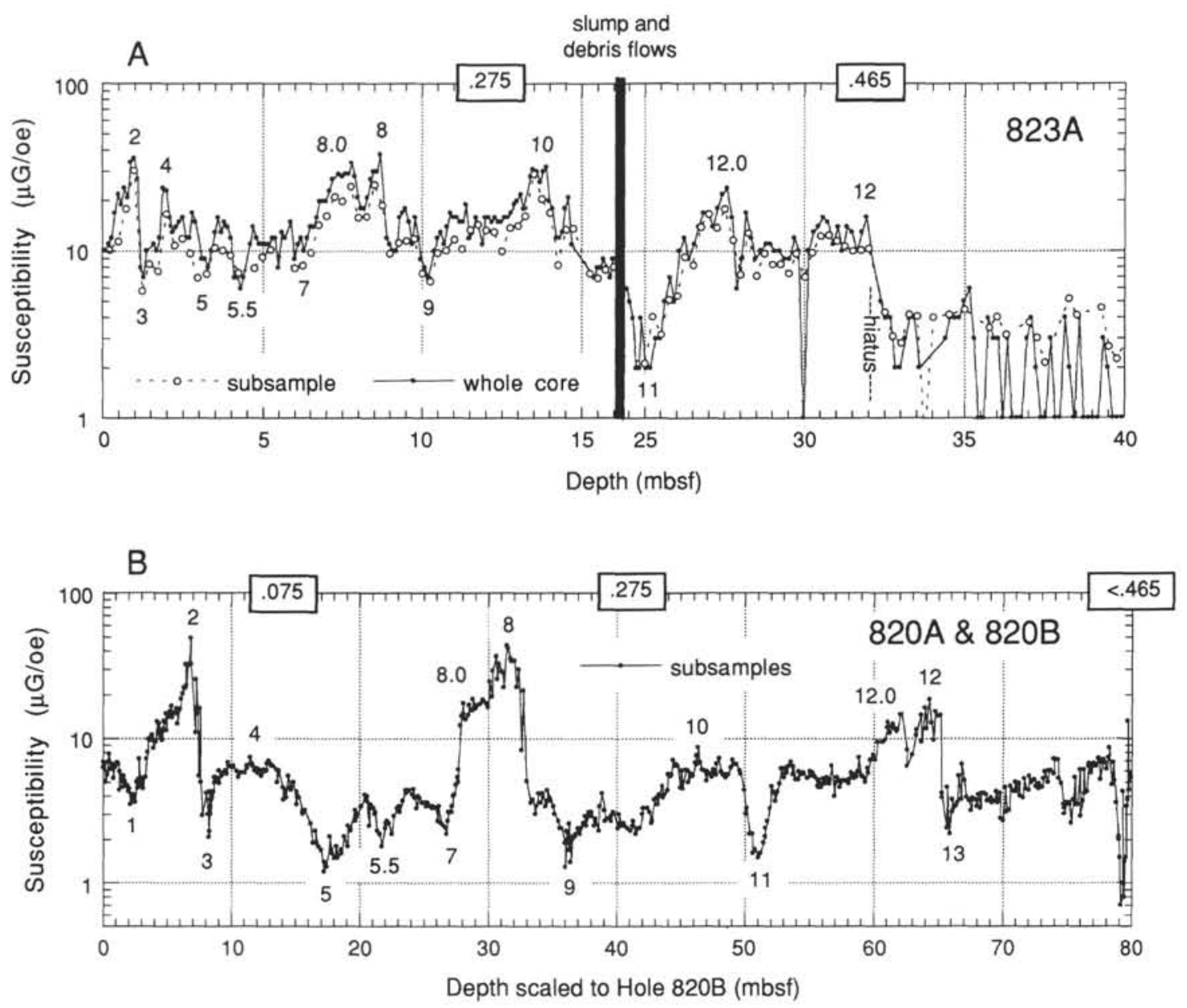

Figure 13. Comparison of susceptibility records for Sites 823 and 820 for the interval from WG/0.465 to WG/0.92. Correlation tie points, as listed in Table 8, are marked in the figure.

WG/0.81 has been identified only at Hole $822 \mathrm{~A}$. However, we can use the susceptibility stratigraphy to estimate its position at Hole $820 \mathrm{~B}$ (at $141 \mathrm{mbsf}$ ), at Hole 820A (at $143 \mathrm{mbsf}$ ), and at Hole 819A (at about $45 \mathrm{mbsf}$ ). At Hole 821 A we suggest that WG/0.81 occurs at about 156 mbsf, although the susceptibility correlation between Sites 821 and 820 is poorly defined in the interval from 120 to 160 mbsf at Hole $821 \mathrm{~A}$.

Our best (but poor) estimates for the boundaries of the Jaramillo Subchron (at Sites 819 and 822) and the Olduvai (at Site 822) have been included in the table. These are consistent with the biostratigraphy for Site 819, but are at odds with WG/0.92 and WG/1.88 at Hole $822 \mathrm{~A}$. The supposed boundaries of the Jaramillo Subchron at Sites 819 and 822 , transposed to Sites 821 and 820 , have not been listed in Table 9 because they are poorly defined and do not agree with WG/0.92 at Sites 821 and 820 .

\section{MINERAL MAGNETIC VARIATIONS}

The last occurrence of Pseudoemiliania lacunosa (0.465 Ma) marks a boundary between two distinct magnetic susceptibility patterns. This boundary is probably associated with a significant change in the evolution and morphology of the GBR. It is convenient to refer to the two susceptibility patterns as pre-GBR and post-GBR, bearing in mind that we are referring to a transition from an earlier form to a present-day-type reef. Alexander et al. (this volume) have identified the interval from the $\mathrm{B} / \mathrm{M}$ boundary to $0.465 \mathrm{Ma}$ with a paleoceanographic transition from a Subtropical Central Water (SCW) circula- tion pattern to intensified circulation under the influence of Antarctic Intermediate Water (AAIW).

\section{Pre-GBR Susceptibility Variations and Cyclic Couplets}

Below WG/0.465, the susceptibility records at all sites display a pattern of cyclic oscillations (see Fig. 10, for example). These cycles correspond to rhythmically bedded hemipelagic carbonate and siliciclastic sand and mud, with well-defined series of upward-coarsening couplets. The couplets are described by Davies, McKenzie, PalmerJulson, et al. (1991), Feary and Jarrard (this volume), Alexander et al. (this volume) and Glenn, Kroon, and Wei (this volume). This cyclic pattern of behavior is particularly evident in the prograding and transitional (i.e., mixed prograding and aggrading) sequences of the upper slope. Feary and Jarrard (this volume) equate the transition interval at 1.01 to $0.76 \mathrm{Ma}$ with establishment of an outer reef barrier that restricted sediment supply to the outer shelf and slope.

The upward-coarsening packages, which are thought to correspond to marine regressions, are characterized by decreasing susceptibility (magnetic mineral concentration). This is consistent with the associated increase in carbonate, decrease in mud, and decrease in $\mathrm{FeO}$. The thin, relatively condensed fining-upward layers at the top of each cycle, corresponding to marine transgressions, are characterized by increasing susceptibility.

A strong inverse correlation exists between susceptibility and calcium carbonate content, as noted by Davies, McKenzie, Palmer-Julson, 
Table 9. Summary of revised chronology.

\begin{tabular}{|c|c|c|c|c|c|c|c|}
\hline \multirow[b]{2}{*}{ Datum } & \multirow{2}{*}{$\begin{array}{l}\text { Age } \\
\text { (Ma) }\end{array}$} & \multicolumn{6}{|c|}{ Hole } \\
\hline & & $821 \mathrm{~A}$ & $820 \mathrm{~A}$ & $820 \mathrm{~B}$ & $819 \mathrm{~A}$ & $822 \mathrm{~A}$ & $823 \mathrm{~A}$ \\
\hline FO Emiliania huxleyi Acme & 0.075 & 12.5 & 11 & 10 & 10 & - & 2.0 \\
\hline FO Emiliania huxleyi & 0.275 & 39.3 & 35.8 & 35.4 & 26.9 & 21.8 & 9.8 \\
\hline LO Pseudoemiliania lacunosa & 0.465 & 121 & 109.5 & 108 & 32.4 & 21.8 & 32.0 \\
\hline Brunhes/Matuyama & 0.73 & 151 & 139.5 & 137 & 40.8 & 51 & 70.? \\
\hline LO Reticulofenestra sp. A & 0.81 & 156 & 143 & 141 & 45 & 54.8 & - \\
\hline Top of Jaramillo & 0.91 & - & & - & $54 ?$ & 83.? & - \\
\hline FO Gephyrocapsa spp. C-D & 0.92 & 176.8 & & 160 & 56.1 & 77.8 & 80.2 \\
\hline Bottom of Jaramillo & 0.97 & - & & - & $65.5 ?$ & $88 ?$ & - \\
\hline LO Gephyrocapsa spp. A-B & 1.10 & 270.1 & & 260.3 & 166.9 & 125.6 & 95.5 \\
\hline LO Helicosphaera sellii & 1.27 & 279.2 & & 271.7 & 189.2 & 220.0 & 105.7 \\
\hline LO Calcidiscus macintyrei & 1.48 & 400 & & 400 & 400 & 301.5 & 150.9 \\
\hline Top of Olduvai & 1.66 & & & & & $339 ?$ & - \\
\hline Bottom of Olduvai & 1.88 & & & & & $360 ?$ & - \\
\hline LO Discoaster brouweri & 1.88 & & & & & 333.4 & 163.0 \\
\hline LO Discoaster pentaradiatus & 2.29 & & & & & 399.3 & 222.3 \\
\hline LO Discoaster surculus & 2.42 & & & & & 411.0 & 236.2 \\
\hline Matuyama/Gauss & 2.47 & & & & & 415 & - \\
\hline LO Discoaster tamalis & 2.60 & & & & & 419.0 & 244.3 \\
\hline
\end{tabular}

Revised chronology is based on the Wei and Gartner's (this volume) biostratigraphic age boundaries, reversal boundaries and susceptibility stratigraphy; bold type $=$ revised or inferred depths; $F O=$ first occurrence; $\mathrm{LO}=$ last occurrence; ? = uncertain assignment.

et al. (1991) and others. Plots comparing these two parameters for Hole $820 \mathrm{~B}$ are given by Barton et al. (this volume). Figure 14 shows the correlation for the post-GBR part of the record at Site 820, and for the complete record at Site 821. Note there is an offset between the prominent susceptibility maxima and the carbonate minima in the post-GBR record at Hole $820 \mathrm{~A}$. The offset was first noted by Peerdeman and Davies (this volume) in the uppermost susceptibility peak at 7 mbsf. Such offsets do not occur in the lower, pre-GBR part of the record. Barton et al. (this volume) show that apart from these peaks, the susceptibility variations are controlled mainly by carbonate content, with variations in terrigenous flux playing a secondary role. This agrees with the conclusion of Feary and Jarrard (this volume) that the mud influx is at a relatively constant "background" rate with varying influxes of carbonate.

Equally striking is the strong inverse correlation between susceptibility and $\delta^{18} \mathrm{O}$ in the pre-GBR sequences (discussed later in this study). Such a relationship indicates that the high-susceptibility/low-carbonate part of each cycle (or couplet) is associated with high sea level, and vice versa. It is also consistent with the paleodepth estimates obtained from benthic foraminifers for Site 820 (discussed by Feary and Jarrard, this volume) which show water depths of 200 to $600 \mathrm{~m}$ for the lowcarbonate/high-susceptibility (lower) part of each cycle, and 100 to 200 $\mathrm{m}$ for the high-carbonate/low-susceptibility (upper) part.

\section{Post-GBR Susceptibility Variations and Sharp Peaks}

Above WG/0.465, in the aggrading sequences of the upper slope sites (Sites 821, 820, and 819) and at Site 823, the pattern is more complicated and contains several sharp susceptibility peaks (see Fig. 2 , for example). The sharp peaks are accompanied by peaks in carbonate content, mud fraction and $\delta^{18} \mathrm{O}$. A close examination of the peaks (Peerdeman and Davies, this volume; Alexander et al., this volume; Barton et al., this volume) indicates that they do not coincide exactly. This is demonstrated most clearly for the last glacial maximum in the upper $10 \mathrm{~m}$ of Site 820 (Peerdeman and Davies, this volume), where the time-sequence of peaks is first carbonate, then $\delta^{18} \mathrm{O}$ and sand fraction together, followed by susceptibility. It is not yet clear whether the pattern is caused by superposition of the sharp susceptibility peaks on the progradational-type background oscillations (Barton et al., this volume), or whether there is a fundamental change in phase relationships between susceptibility and the other parameters after $0.465 \mathrm{Ma}$ (Alexander et al., this volume).
The prominent susceptibility peaks in the post-GBR sequences are associated with glacial maxima, and generally share a common morphology. The cycle starts with a rapid rise from low susceptibility to a sharp maximum, followed by a gradual decline (but still remaining high), and finally a more rapid decline to low values. This pattern is particularly clear at Site 820 (Fig. 2). At Site 821 the initial rise to a maximum susceptibility is less abrupt.

Peerdeman and Davies (this volume) examine the record of the last glacial maximum at Hole $820 \mathrm{~A}$ in great detail and conclude that it is the initial low and abrupt rise in susceptibility that correlate with the peak in $\delta^{18} \mathrm{O}$ (and a peak in sand fraction) and, hence, correspond to minimum sea level. The abruptness of the rise is exaggerated by low sedimentation rates during this interval. The sharp peak in susceptibility and the subsequent gentle decline at high values correspond to the early stage of transgression. During the later stage of regression, susceptibility relaxes to low values and remains relatively low during the interglacial. Smaller amplitude oscillations in susceptibility occur between the main peaks. The similarity in magnetic properties between these smaller oscillations and the pre-GBR oscillations at Site 820 led Barton et al. (this volume) to conclude that the glacial signal has been superimposed on a "background" pattern of variations. The offset in peaks near a glacial maximum is largely responsible for the positive correlation between susceptibility and $\delta^{18} \mathrm{O}$ in the post-GBR sequences noted by Alexander et al. (this volume) for Site 819, and by Barton et al. (this volume) for Site 820 .

\section{Types of Magnetic Properties}

Preliminary examination of the magnetic properties of sediments from Site 820 (Barton et al., this volume) revealed three distinct classes of behavior. The distinction shows up most clearly in the ratio of volume susceptibility $(K)$ to ARM, but also in several other properties (e.g., MDF, $Q$-ratio, and SIRM $/ K$ ). Pre-GBR sediments (the "background" signal) have very low K/ARM ratios, and carry a soft MD-remanence with some ultrafine SP contribution (type-A properties). The sharp susceptibility peaks carry a SD remanence having a significant super-paramagnetic contribution (type-C properties). During the late regression (i.e., the broad, gently declining part of the susceptibility peak), the remanence has maximum stability and appears to be of pure SD magnetite origin (type-B properties). Barton et al. (this volume) report that only the top three prominent susceptibility peaks at Site 820 displayed type-B and type-C properties, and 

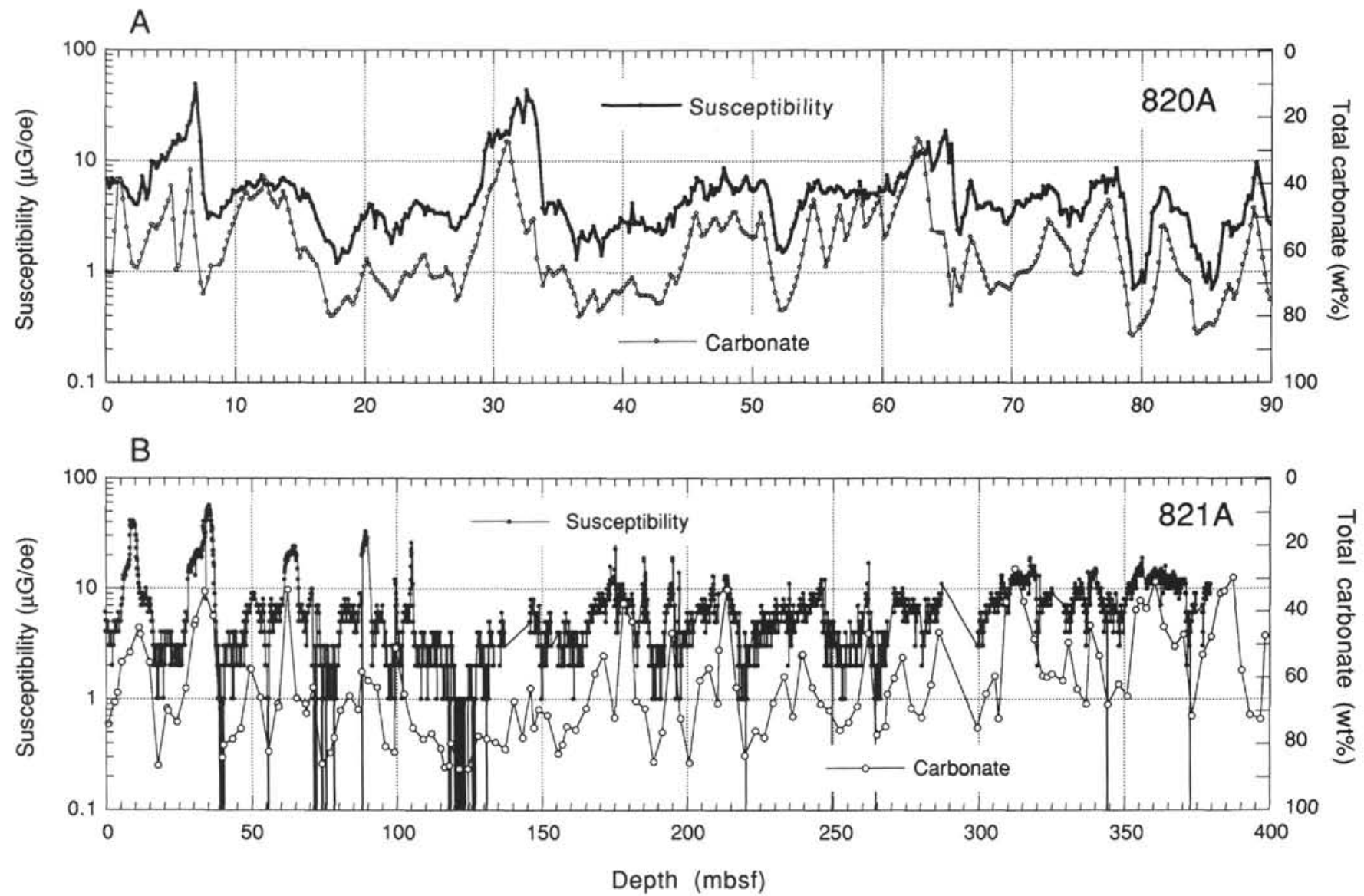

Figure 14. Comparison of magnetic susceptibility and total calcium carbonate content records. A. Upper 90 mbsf at Hole $820 \mathrm{~A}$, carbonate data from Feary and Jarrard (this volume); subsample susceptibility data from Barton et al. (this volume). B. Hole $821 \mathrm{~A}$, carbonate and whole-core susceptibility data from Davies, McKenzie, Palmer-Julson, et al. (1991).

that the lesser peaks lower in the sequence had essentially type-A properties. Because of the strong correlation between prominent peaks at all sites (except Site 822), we assume that the types of magnetic properties at Site 820 are characteristic of the other sites. Alexander et al. (this volume) point out that below $35 \mathrm{mbsf}$ at Site 819 (i.e., below WG/0.465), $S$-ratios are lower in the glacial intervals and higher in the interglacials. They argued that this probably indicates a finer magnetic grain size spectrum in the glacials. This is consistent with the sediment magnetic property classification for Site 820 . The nature of the peaks at Site 823 are discussed further by Barton (this volume).

It has been suggested that the sharp peaks in Hole 819A at 21.7 and 24.6 mbsf may be dissolution relics (Alexander et al., this volume), i.e., the result of glacial-related variations in geochemical conditions and deposition rates. The apparent uniformity of the magnetic mineralogy through the post-GBR sequences supports this view. However, one would expect that reduced dissolution would be accompanied by higher sedimentation rates, which is not the case for the sharp susceptibility maxima. The role of dissolution in controlling the magnetic signal therefore remains an open question.

Evidence of bacterial magnetite has been found at several sites by P. Hesse (pers. comm., 1991, see Barton et al., this volume) using electron microscopy, and by D. McNeill (pers. comm., 1992) using ARM acquisition characteristics. Hesse noted that the relative abundance of bacterial magnetite chains is directly related to the total magnetic mineral concentration. Further evidence for the presence of biogenic magnetite comes from the apparently common occurrence of magnetite near the SP/SD-size threshold at Site 820 (an abundance of crystals in the pure SD size range is symptomatic of a biogenic origin, and partial dissolution would shift the grain-size spectrum toward the SP/SD threshold). However, not enough work has yet been done to gauge the importance of biogenic magnetite in these sediments.

\section{$\delta^{18} \mathrm{O}$ and Magnetic Susceptibility}

Peerdeman et al. (this volume) and Peerdeman and Davies (this volume) note that the magnetic susceptibility and planktonic oxygen isotope records for Site 820 are closely related. They point out that the prominent sharp susceptibility peaks coincide with $\delta^{18} \mathrm{O}$ maxima (minimum sea level). When a longer record length is considered (Barton et al., this volume), it is apparent that this positive correlation between the two records is characteristic only of post-GBR peak glacial conditions and during the Holocene, and that throughout most of the record there is a strong inverse correlation between $\delta^{18} \mathrm{O}$ and susceptibility. The upper 95 mbsf at Hole 820A illustrates the relationships (Fig. 15). The inverse correlation is even more striking and consistent in the record beneath 95 mbsf (see Barton et al., this volume). Above the glacial maximum at $33 \mathrm{mbsf}$ at Site 820 (corresponding to $35 \mathrm{mbsf}$ at Site 821 and 25 mbsf at Site 819 ) the well-defined interglacial inverse correlation no longer exists, which indicates that a simple model of identical repeating glacial cycles is oversimplistic.

The only other site for which oxygen isotope data are currently available is Site 819 (Alexander et al., this volume). Sites 820 and 819 are only $2.7 \mathrm{~km}$ apart; thus, we might expect their isotope records to be alike. In fact, this is not so, and only the last glacial maximum corresponds unambiguously in each record, as illustrated for the 


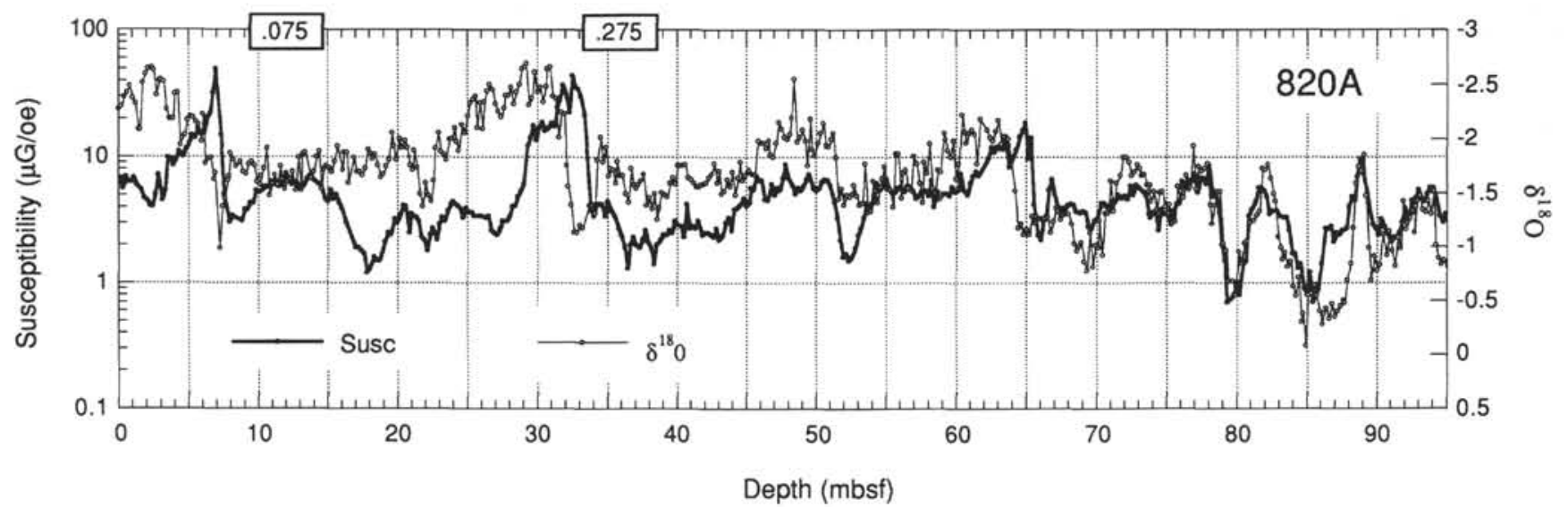

Figure 15. Volume susceptibility and planktonic foraminifer (G. ruber) $\delta^{18} \mathrm{O}$ records for the upper $95 \mathrm{~m}$ of Hole $820 \mathrm{~A}$. Note that the $\delta^{18} \mathrm{O}$ scale is reversed. Over most of the record can be seen a strong inverse correlation. This breaks down toward the top of the record. The $\delta^{18} \mathrm{O}$ maxima (glacial maxima) at 7,33, and 65 mbsf are linked to sharp susceptibility maxima.
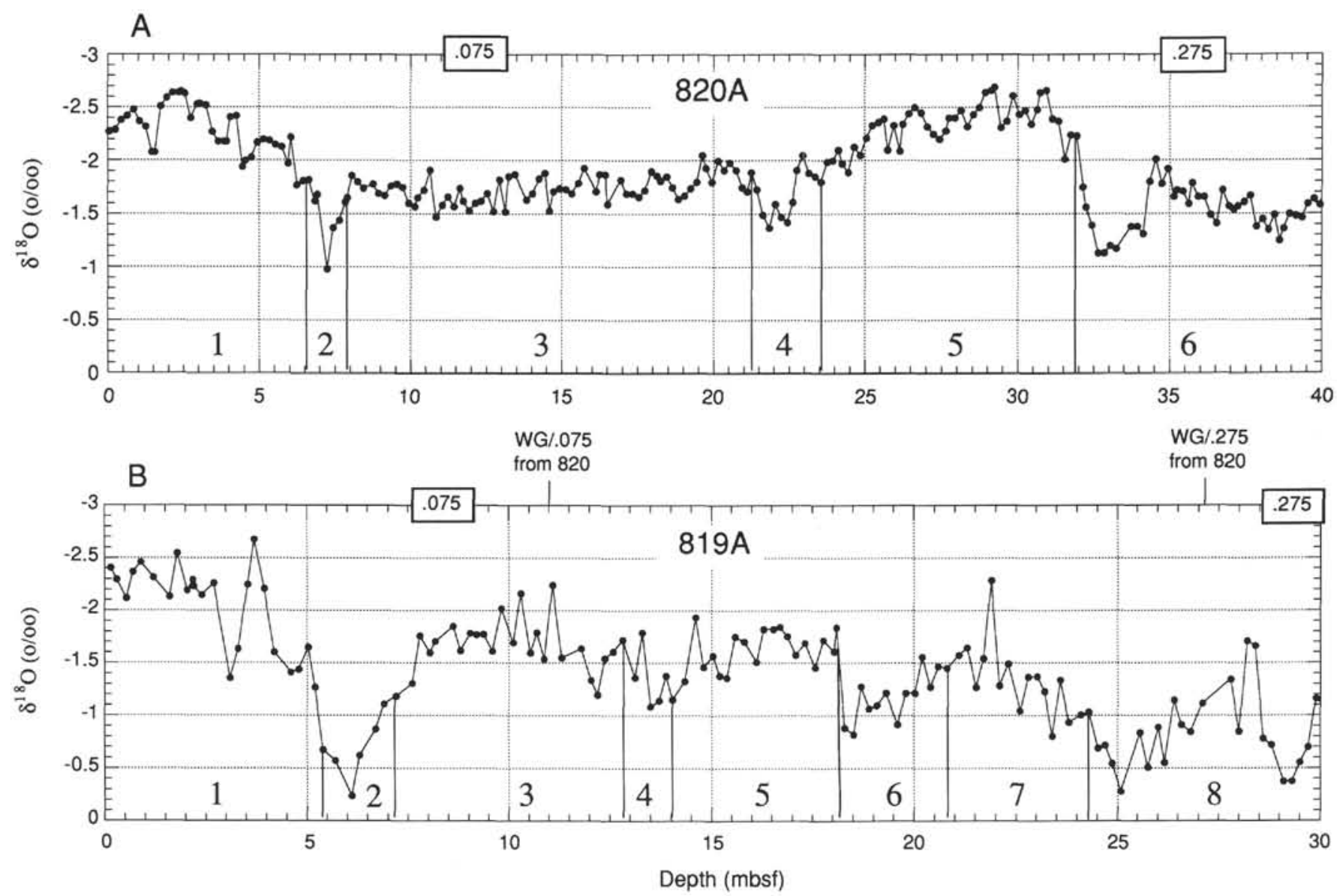

Figure 16. Planktonic foraminifer (G. ruber) $\delta^{18} \mathrm{O}$ records for the upper parts of (A) Hole 820A, data from Peerdeman et al. (this volume), and (B) Hole 819A, data from Alexander et al. (this volume). The isotopic stage interpretations of the respective authors are marked in the figure.

upper parts of the records in Figure 16. For example, the prominent isotope stage $5 / 6$ boundary, which stands out at Site 820 (placed at 32 mbsf by Peerdeman et al., this volume), is subdued at Site 819 (placed at 18 mbsf by Alexander et al., this volume). The isotopic stage interpretations of Peerdeman et al. (this volume) and Alexander et al. (this volume) are shown on the figure.
Plots comparing specific magnetic susceptibility with planktonic $\delta^{18} \mathrm{O}\left(G\right.$. ruber) and with benthic $\delta^{18} \mathrm{O}$ (Cibicidoides wuellerstorfi) at Hole 819A are shown in Figure 17 (data from Alexander et al,, this volume). Note that specific susceptibility (i.e., susceptibility per unit mass) and whole-core volume susceptibility records for Site 819 have the same morphology, thus either parameter may be used in the present 


\section{C.E. BARTON ET AL.}
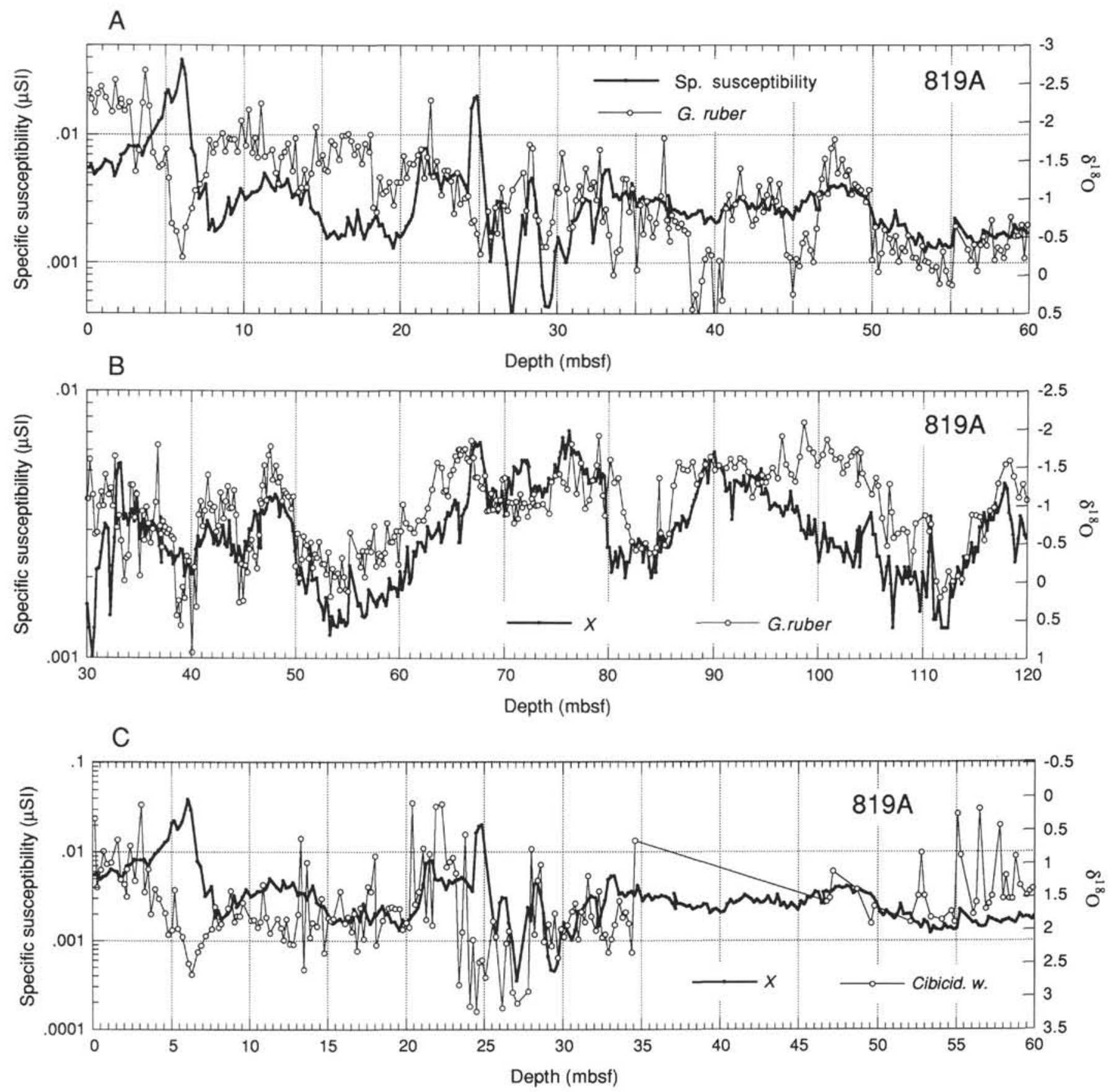

Figure 17. Specific susceptibility and $\delta^{18} \mathrm{O}$ records for Site 819. A. Susceptibility and the $G$. ruber planktonic $\delta^{18} \mathrm{O}$ record. B. Re-scaled version of the lower part of A. C. Susceptibility and $C$. wuell. benthic $\delta^{18} \mathrm{O}$ record. Data from Alexander et al. (this volume). The specific susceptibility records plotted in these figures have the same morphology as the shipboard volume susceptibility records.

context. Evidently, the well-defined correlations that exist between $\delta^{18} \mathrm{O}$ and susceptibility at Site 820 are less clear at Site 819 , but are still readily identifiable. Allowance must be made for the hiatus at Site 819 at $32.5 \mathrm{mbsf}$ and the low amplitude of the susceptibility record below this depth. The lower, pre-GBR part of Figure 17A has been replotted in Figure 17B to show more clearly the inverse correlation. A change in phase relationships is apparent at $34 \mathrm{mbsf}$ at Site 819 . Above this level, phase relationships are more varied, with a predominantly positive correlation between susceptibility and planktonic $\delta^{18} \mathrm{O}$.

The upper two sharp susceptibility peaks at 7 and 33 mbsf at Site 820 , which correlate positively with sharp $\delta^{18} \mathrm{O}$ maxima, have counterparts at 6 and 25 mbsf at Hole 819A, respectively (Figs. 2 and 11).
Furthermore, both features have similar biostratigraphic ages at the two sites. This is strong evidence that Peerdeman et al.'s (this volume) assignment of stage 6 to the 33 mbsf maximum at Hole $820 \mathrm{~A}$ and Alexander et al.'s (this volume) assignment of stage 8 to the $25 \mathrm{mbsf}$ maximum at Hole 819A are incompatible. In fact, to make the isotopic stage assignments compatible with the susceptibility correlation scheme shown in Figure 11, we must either (1) change Peerdeman et al.'s stages 4 and 6 to stages 6 and 8, respectively, and insert stage 4 at about 14 to $15.5 \mathrm{mbsf}$ in the middle of the existing stage 3 , or (2) change Alexander et al.'s stages 6 and 8 to stages 4 and 6, respectively, and delete stage 4 . A discussion of the ramifications of these changes and their relative merits is beyond the scope of this paper. 


\section{DISCUSSION}

There is general agreement that the low carbonate contents and high mud fractions that produce high magnetic susceptibility (i.e., high magnetic mineral contents) are associated with glacial/lowstand periods. Conversely, high carbonate contents and low mud fractions (low susceptibility) were produced during intervals of high/rising sea level. This relationship is consistent with the observed correlations between $\delta^{18} \mathrm{O}$ and carbonate content, mud fraction, and susceptibility. The explanation offered by P. Davies (pers. comm., 1991) and others is that at low sea level, carbonate production on the shelf is suppressed and sites on the slope receive more terrigenous sediment from a closer shoreline. As sea level rises to flood the shelf region, reefal communities are reactivated, thus producing more carbonate detritus onto the slope. Furthermore, the formation of reefs along the outer edge of the shelf probably serves as a barrier to terrigenous sediments.

Glenn, Kronen, et al. (this volume) identified maximum flooding surfaces at Sites 819 and 821 (i.e., condensed sections sandwiched between transgressive and highstand systems tracts) with the high susceptibility peaks. On the other hand, Peerdeman and Davies (this volume) conclude on the basis of the detailed $\delta^{18} \mathrm{O}$ record from Site 820 that the high susceptibility peaks in the post-GBR record occur during, or shortly after, glacial maxima (i.e., at lowstands of sea level). This interpretation is confirmed by their radiocarbon ages for the top $10 \mathrm{~m}$ at Site 820 , which show that the susceptibility peak occurs near the last glacial maximum. As the prominent susceptibility peaks in the upper sections of Sites 821, 820, and 819 appear to correlate, we adopt the low sea-level interpretation of Peerdeman and Davies.

It is not clear whether the GBR, in its present form, became established during the seismic geometry transition at 1.01 to $0.76 \mathrm{Ma}$ (Feary and Jarrard, this volume), or significantly later at about $0.4 \mathrm{Ma}$ (Davies and Peerdeman, pers. comm., 1992). Feary and Jarrard (this volume) conclude that the transition from progradation to aggradation coincides with the development of an effective reefal barrier on the outer shelf. Such a barrier would restrict the supply of sediment to the slope, causing lower sedimentation rates, and would also focus sediment through outlet channels between reefs. Davies and Peerdeman (pers. comm., 1992) consider that the change in amplitude and frequency of the $\delta^{18} \mathrm{O}$ record for Site 820 at about $0.4 \mathrm{Ma}$ (near WG/0.465) may delineate the major change to more intense glacial/interglacial contrasts that characterize the upper part of the record. They linked this change to the development of the GBR in its present form.

Magnetic data have some bearing on the question. The main magnetic boundary occurs in the vicinity of WG/0.465. First, the sharp susceptibility peaks occur only above WG/0.465, and the change in phase relationships between susceptibility and $\delta^{18} \mathrm{O}$ noted for Site 819 occur just below WG/0.465. Second, sediments accumulating in the trough are expected to be sensitive to major events on the shelf, and, indeed, at Site 823 we find a major change in magnetic properties across the boundary at $32 \mathrm{mbsf}$ (WG/0.465) (Barton, this volume). Finally, magnetic properties in the interval from WG/0.465 down to, and including, the seismic geometry transition zone are generally similar to those in the prograding sequences (type-A). This evidence favors the view that the post-GBR sedimentary regime (as defined herein) was initiated at about $0.4 \mathrm{Ma}$.

Records from all sites except Site 819 display a zone of reduced susceptibility in the interval from the B/M boundary to WG/0.465, probably nearer 0.7 to $0.4 \mathrm{Ma}$, in which cyclic variations in susceptibility are subdued and carbonate is increased. (This is the interval associated with a paleoceanographic change from SCW- to AAIW-dominated circulation patterns proposed by Alexander et al., this volume). The effect can be seen in Figures 2 and 10 and is particularly evident at Site 823. The onset of reduced susceptibility occurs at the end of the transition period, close to the $\mathrm{B} / \mathrm{M}$ boundary (in fact, it can be used to deduce that the B/M boundary at Site 823 lies near $70 \mathrm{mbsf}$ ).

Thus, the magnetic evidence points to a two-stage development of the GBR. First, an outer reef barrier formed that is marked by the seismic geometry transition and was responsible for restriction of the sediment supply to the slope. This was accompanied by a fall in susceptibility (terrigenous content) that was most pronounced following the $\mathrm{B} / \mathrm{M}$ boundary. The second stage occurred at about $0.4 \mathrm{Ma}$ and marked the onset of much greater variability in the sedimentary record and associated magnetic properties (the post-GBR sequences referred to here). The two stages of reef development clearly raise questions about the relative importance and inter-relationship of reef morphology and changes in climatic conditions/ocean circulation as factors controlling sedimentation.

An explanation needs to be found for the type-A, -B, and -C magnetic properties, defined by Barton et al. (this volume), that characterize glacial/interglacial cycles in the post-GBR sequences, particularly the super-paramagnetic content of the sharp susceptibility peaks. Glenn, Kroon, and Wei (this volume) and also Barton et al. (this volume) discuss the possibility that the peaks at or near glacial maxima have been produced by a large influx of wind-borne material from an arid continental interior. Such occurrences are well documented in other regions and are known to produce high SP contents and enhanced susceptibility (e.g., Bloemendal et al., 1988). However, as pointed out by both P. Hesse and R. Wasson (pers. comm., 1992) and documented by Thiede (1979), the prevailing southeasterly wind pattern over northeastern Australia became intensified during glacial conditions and did not produce significant dust lobes out to sea. For this reason, an aeolian explanation for the sharp susceptibility peaks is discounted (although there remains the possibility that more very fine-grained aeolian material entered the eastern catchments of the continent during glacial maxima and was transported by rivers and streams onto the shelf). Exposure and submergence of the shelf during glacial and interglacial cycles may be important for determining the type of magnetic particles that reached the slope. To illustrate this, we present a biomagnetic inter-reefal estuarine reservoir (BIER) hypothesis:

1. At low sea-level, much of the shelf was exposed and fine-grained detritus was trapped in river estuaries and deltas. Reefs on the outer edge of the shelf acted as barriers and further restricted the sediment flux to the slope. At the same time, bacterial magnetite accumulated in inter-reefal lagoons and swamps. Reefal carbonate communities were inactive and carbonate contents in the sediments were low. The supply of terrigenous sediment to the slope occurred through gaps in the reef (Harris et al., 1990), and sedimentation rates were low. The estuarine and deltaic reservoirs of terrigenous detritus would have been greatest toward the outer edge of the shelf where topographic gradients were lowest, and it is here that the finest particles accumulated.

2 . At the beginning of the early transgression, these reservoirs were tapped and resulted in the initial flush of superfine products of winnowing that account for the sharp susceptibility peaks with high $\mathrm{SP}$ and biomagnetic (SD) contents.

3. As transgression proceeded, more distal (shoreward) fluviodeltaic reservoirs also were accessed, which, together with material from the proximal reservoirs, produced sediments having slightly coarser, predominantly SD characteristics.

4. As interglacial highstand conditions were established, the reefal carbonate communities flourished and carbonate contents in the sediments rose, increasing the sediment-accumulation rate, diluting the terrigenous influx, and lowering susceptibility. Average particle size increased as a consequence of more vigorous offshore transport processes (shelf currents, storms, intensified boundary currents), probably combined with more precipitation and greater runoff from the eastern side of the continent. The establishment of relatively coarse, MD (type-A) background properties under these conditions probably was enhanced by gradual dissolution of very fine magnetic grains.

The evidence to sustain the hypothesis is limited and certain counterarguments can be made (Feary, pers. comm., 1993). Nevertheless, the hypothesis provides a starting point for discussion and illustrates the kind of scenarios that must be considered to explain the observed 
variations in magnetic properties at Site 820 (and, by implication, also at Sites 821 and 819).

Only Site 823 contains a sufficiently long record to monitor long-term paleoceanographic changes. Little effort has yet been devoted to examining this. We note only that there is a broad high in the Site 823 susceptibility record at from about 800 to $720 \mathrm{mbsf}$ (Unit V, 6.3-5.5 Ma), which corresponds to the Cenozoic cooling and onset of Antarctic glaciation proposed by Kennett and co-workers (e.g., Kennett and von der Borch, 1985; see Chamley et al., this volume, for further discussion). Cooling favored physical rather than chemical weathering, with a consequent increase in the terrigenous flux and a corresponding rise in susceptibility. This interval is also thought to mark the beginning of the uplift of the Eastern highlands of Australia (e.g., Chamley et al., this volume).

The difficulties of correlating between Sites 820 and 819 , which are separated by a distance of only $2.7 \mathrm{~km}$, illustrate the problems of coping with the big fluctuations in sedimentation rate, slumps, and missing intervals that are common in upper slope sequences. This necessitates great caution when applying standard time-series analysis techniques (which assume stationarity) to identify Milankovitch periodicities.

\section{CONCLUSIONS}

Magnetostratigraphic results from Sites 819 through 823 are generally poor because of VRM effects and pervasive overprinting. Only a few reversal boundaries can be identified with any certainty. Preliminary shipboard polarity interpretations (Davies, McKenzie, Palmer-Julson, et al., 1991) failed to recognize the extent of overprinting and were at times at odds with the biostratigraphic ages. The interpretations presented here have been based on additional subsample data and rely heavily on a magnetic susceptibility stratigraphy. Intersite susceptibility correlations demonstrate that the calcareous nannofossil stratigraphy of Wei and Gartner (this volume) is highly consistent. A revised chronology has been devised to optimize agreement with the susceptibility stratigraphy (Table 9). This chronology fine-tunes the Wei and Gartner chronology and incorporates our best estimates of the positions of some of the poorly resolved reversal boundaries.

Paleomagnetic remanence signals at the middle and lower slope sites (Sites 819 and 822) are better than those at the upper slope sites (Sites 821 and 820) and at the Queensland trough (Site 823). Dissolution provides an explanation for this difference in magnetic stability among sites. The residence time of primary magnetic oxides (principally magnetite) in the surface reducing zone is longest for the sites that have the poorest magnetic records and the highest incidence of overprinting. It is also possible that the middle to lower slope regions have lower MD contents.

Magnetic susceptibility is central to identifying relationships with sedimentological, geochemical, and isotopic parameters, which all respond to sea-level fluctuations and are strongly influenced by the development of the GBR. There are three patterns of susceptibility behavior. The dominant pattern is a background series of cyclic oscillations seen in the prograding and transitional sequences on the upper slope (i.e., pre-B/M boundary time). The cyclic susceptibility variations are controlled more by carbonate dilution than by changes in terrigenous influx. These susceptibility cycles are thought to correspond to cyclic variations in glacio-eustatic sea-level variations - high susceptibility and low carbonate at high sea level, an upward-coarsening interval during the following regression, followed by low susceptibility and high carbonate at low sea levels. This behavior is reflected in a strong inverse correlation between susceptibility and carbonate content.

The interval from the $\mathrm{B} / \mathrm{M}$ boundary to about $0.4 \mathrm{Ma}$ is characterized by relatively low susceptibility with less-pronounced cyclic variations. This interval is associated by Alexander et al. (this volume) with a change from SCW to AAIW circulation patterns off northeastern Australia. The boundary at about $0.4 \mathrm{Ma}$ is where a change in the amplitude and frequency of the $\delta^{18} \mathrm{O}$ record at Site 820 was identified by Peerdeman et al. (this volume).

After about $0.4 \mathrm{Ma}$, several prominent susceptibility peaks are superimposed on a cyclic background signal. This occurs in the progradational sequences on the shelf edge and upper slope (at Sites 821, 820 , and 819 ). The peak pattern is thought to reflect the sedimentological response to sea-level fluctuations after establishment of the GBR. The prominent peaks have a characteristic morphology. They show a rapid rise to a pronounced maximum associated with glacial maximum (minimum sea level) conditions. Sedimentation rates were very low during this time; hence, the rapid onset is exaggerated. The magnetic signature is dominated by a mixture of SD and SP magnetite (type-C properties). During the early stage of the sub- sequent transgression, susceptibility started to decrease, though still remained high, and the magnetic mineralogy was predominantly pure SD magnetite (type-B properties). Glacial maximum and early transgression intervals have the most stable magnetic remanence with relatively high $\mathrm{MDF}$ and $Q$-ratios. During the later stage of regression, susceptibility gradually fell, assuming low values during sea-level highstands.

Water depth clearly is an important factor determining the amplitude of susceptibility variations and also the degree and nature of correlations with oxygen isotope records. At Site 820 (present water depth $278 \mathrm{~m}$ ) we find larger amplitude variations in susceptibility and a clearer correlation with $\delta^{18} \mathrm{O}$ than at Site 819 (present water depth 565 $\mathrm{m})$. Such differences indicate that water depth should be a major consideration when investigating relationships between isotopic, sedimentological, and magnetic parameters in shelf and slope environments.

Results from Sites 819 and 820 show that the susceptibility records correlate more easily among sites than do the oxygen isotope records. Therefore, merit can be found in using susceptibility for comparing isotopic stage assignments and, under appropriate circumstances, as a proxy for $\delta^{18} \mathrm{O}$.

The magnetic evidence supports a two-stage development of the GBR. First, there is a change in geometry as an outer reef barrier forms, restricting the supply of sediment to the slope. This is seen as a general decrease in susceptibility (terrigenous influx) after the B/M boundary. The second stage, occurring after about $0.4 \mathrm{Ma}$, is thought to relate to changes in the morphology and sediment dynamics on the reef and slope, resulting in the prominent susceptibility peaks immediately after glacial maxima.

\section{ACKNOWLEDGMENTS}

We thank the many authors cited from this volume for providing preprints of their chapters and data files, particularly Dick Kroon and David Feary, and also Peter Davies, David Feary, Phil Symonds and Chris Klootwijk for helpful discussions and comments. This study is published with permission from the Executive Director, Australian Geological Survey Organisation.

\section{REFERENCES ${ }^{*}$}

Barton, C.E., and Bloemendal, J., 1985. Paleomagnetism of sediments collected during Leg 90, Southwest Pacific. In Edgar,N.T., Saunders, J.B., et al., Init. Repts. DSDP, 15: Washington (U.S. Govt. Printing Office), 1273-1316.

Berggren, W.A., Kent, D.V., and Flynn, J.J., 1985a. Neogene geochronology and chronostratigraphy. In Snelling, N.J. (Ed.), Geochronology and the Geological Time Scale. Geol. Soc. London Mem., 10:211-260.

Berggren, W.A., Kent, D.V., and Flynn, J.J., 1985b. Paleogene geochronology and chronostratigraphy. In Snelling, N.J. (Ed.), Geochronology and the Geological Time Scale. Geol. Soc. London Mem., 10:141-195.

Bloemendal, J., Lamb, B., and King, J., 1988. Paleoenvironmental implications of rock-magnetic properties of late Quaternary sediment cores from the Eastern Equatorial Atlantic. Paleoceanography, 3:61-87.

\footnotetext{
- Abbreviations for names of organizations and publication titles in ODP reference lists follow the style given in Chemical Abstracts Service Source Index (published by American Chemical Society).
} 
Cande, S.C., and Kent, D.V., 1992. A new geomagnetic polarity time scale for the Late Cretaceous and Cenozoic. J. Geophys. Res., 97:13917-13951.

Davies, P.J., McKenzie, J.A., Palmer-Julson, A., et al., 1991. Proc. ODP, Init. Repts., 133: College Station, TX (Ocean Drilling Program).

DeMenocal, P.B., Ruddiman, W.F., and Kent, D.V., 1990. Depth of post-depositional remanence acquisition in deep-sea sediments: a case study of the Brunhes-Matuyama reversal and oxygen isotopic stage 19.1. Earth Planet Sci. Lett., 99:1-13.

Dunlop, D.J., 1973. Superparamagnetic and single-domain threshold sizes in magnetite. J. Geophys. Res., 78:1780-1793.

Harris, P.T., Davies, P.J., and Marshall, J.F., 1990. Late Quaternary sedimentation on the Great Barrier Reef continental slope east of Townsville, Australia. Mar. Geol., 94:55-77.

Karlin R., and Levi, S., 1983. Diagenesis of magnetic minerals in recent hemipelagic sediments. Nature, 303:327-330.
Kennett, J.P. and von der Borch, C.C., 1985. Southwest Pacific Cenozoic paleoceanography. In Kennett, J.P., von der Borch, C.C., et al., Init. Repts. DSDP, 90: Washington (U.S. Govt. Printing Office), 1493-1517.

Moon, T., and Merrill, R.T.,1986. A new mechanism for stable viscous remanent magnetization and overprinting during long magnetic polarity intervals. Geophys. Res. Lett., 13:737-740.

Thiede, J., 1979. Wind regimes over the late Quaternary southwest Pacific Ocean. Geology, 7:259-262.

Thompson, R., and Oldfield, F., 1986. Environmental Magnetism: London (Allen and Unwin).

Date of initial receipt: 21 April 1992

Date of acceptance: 15 June 1993

Ms 133SR-285 